\title{
Two-component theory of the suffix effect: Contrary evidence
}

\author{
LANCE C. BLOOM \\ Rice University, Houston, Texas
}

\begin{abstract}
The suffix effect is the selective impairment in recall of the final items of a spoken list when the list is followed by a nominally irrelevant speech item, or suffix. It is widely assumed to comprise a bottomup, or structural, effect restricted to the terminal item and a top-down, or conceptually sensitive, effect confined to the preterminal items. Reported here are eight experiments that challenge this view by demonstrating that the terminal suffix effect, as well as the preterminal suffix effect, is susceptible to conceptual influence. The entire suffix effect may be better conceived of as a phenomenon arising from perceptual grouping.
\end{abstract}

The stimulus suffix effect, or suffix effect, is the impairment in recall caused by appending a nominally irrelevant speech item, or suffix, to the end of a spoken sequence (Crowder, 1967; Dallett, 1965). This impairment is always largest at the final position, but it typically occurs at each of the last three or so positions (Crowder, 1967, 1976; Crowder \& Morton, 1969) and not infrequently extends back even further into the sequence (Engle, 1974, 1980; Greene, 1992; Morton, Crowder, \& Prussin, 1971; Nairne, 1990; Penney, 1979). The impairment has been found to be nearly as large as that caused by adding another to-be-remembered item to the list (e.g., Crowder, 1967, Experiment 3; Frick, 1988). The implication is that, for all intents and purposes, explicit instructions either to ignore the suffix or to treat it as a mere recall signal cannot be heeded.

The suffix effect has received numerous theoretical treatments (for recent reviews, see Greene, 1992; Neath \& Surprenant, 2003), but the historically most influential is the first - namely, the theory of precategorical acoustic storage, or PAS (Crowder, 1978; Crowder \& Morton, 1969; see also Greene, 1992; Greene \& Crowder, 1984b; Morton, Marcus, \& Ottley, 1981). This is an informationprocessing theory, with PAS conceived of as a peripheral structure that retains speech-related information in a relatively raw (precategorical) form for at least 2 sec. PAS initially was assumed to retain only acoustic information (Crowder, 1978; Crowder \& Morton, 1969) but, subse-

This research was supported by National Institute of Mental Health Grant MH35873 to Michael J. Watkins. I am indebted to Michael Watkins for providing comments on earlier drafts of the manuscript. I also thank Marion Willetts for assistance with procedural development. Correspondence concerning this article should be addressed to L. C. Bloom, Department of Psychology, Rice University, Houston, TX 77251-1892 (e-mail: LCBL001@alumni.rice.edu).

Note-This article was accepted by the previous editorial team, when Colin M. MacLeod was Editor. quently, was assumed also to retain gesticulatory information (e.g., Greene \& Crowder, 1984b; Morton et al., 1981) and, thereby, accommodate suffix effects obtained with silently mouthed and lipread stimuli (e.g., Greene \& Crowder, 1984b; Spoehr \& Corin, 1978). The suffix is assumed to overwrite the information in PAS.

Such overwriting theories, and the PAS theory in particular, have garnered much supporting evidence (for reviews, see Crowder, 1976; Greene, 1992; Neath \& Surprenant, 2003). In particular, extensive research has demonstrated that the suffix effect is susceptible to bottom-up, physical manipulations that can be assumed to have their effect at the precategorical level. For example, the effect of the suffix is attenuated if it is presented from an apparent location or in a voice different from that for the list items (see, e.g., Morton et al., 1971). Also, a nonspeech suffix, such as a buzzer, following a list of verbal items has no discernible effect (e.g., Crowder, 1972; Morton et al., 1971).

There are also numerous findings that are consistent with the theory's prediction that the suffix effect is immune to top-down, conceptual and strategic manipulations that can be presumed to operate at the postcategorical level. For example, recall of a list of digits is unaffected by whether the suffix is, for example, the word zero, rosy, naught, or $u$ h or a speech utterance played backward (see, e.g., Crowder \& Raeburn, 1970; Morton et al., 1971), and the recall of a sequence of items drawn from a particular conceptual category (e.g., kitchen utensils or animals) is unaffected by whether the suffix is drawn from the same or from a different category (e.g., Morton et al., 1971). Also consistent with the theory is the finding that manipulating attentional - and presumably, concomitant rehearsalstrategies tends not to influence the suffix effect (e.g., Hitch, 1975; Nairne \& Crowder, 1982; see also Crowder, 1967, Experiment 3; Greene, 1992). Furthermore, suffix effects should not, according to the PAS theory, occur with static visual presentation, because iconic information is too fleeting to contribute to recall in a typical suffix effect procedure, meaning that recall should be an entirely 
postcategorical phenomenon. Such suffix effects occasionally have been reported (Frick \& De Rose, 1986a, 1986b; Hitch, 1975), but they tend to be small and not always replicable (Greene, 1987; see also Engle, 1974). In addition, because visual and auditory channels are assumed not to meet prior to the categorization of information into words (Crowder, 1976, p. 59), even an auditory suffix should not produce a typical suffix effect on the recall of visual list items (see Crowder, 1976; Crowder \& Morton, 1969). By and large, this prediction has been confirmed (e.g., Morton \& Holloway, 1970; see also Crowder, 1976). Finally, and also consistent with the PAS theory, bimodal presentation yields a pattern of results that is just about identical to that obtained with purely auditory lists (e.g., Crowder, 1970; see also Crowder, 1976; Greene \& Crowder, 1984b; Greene, Elliott, \& Smith, 1988; Nairne \& Walters, 1983).

Not all of the relevant evidence is consistent with the PAS theory, however. Practice with the task (Balota \& Engle, 1981; see also Penney, 1985), attention to the suffix in interaction with change of voice for the suffix presentation (Greenberg \& Engle, 1983), and predictability of list length (Penney, 1985) are variables that might reasonably be presumed to affect the participant's strategies or other top-down processes, and yet all have been found to modulate the suffix effect. These empirical difficulties have led not to the rejection of the PAS theory, but merely to its modification. It so happened that the effect of each of these three variables was observed at the preterminal positions of the suffix effect, but not at the last position. Accordingly, the PAS theory of the suffix effect was revised into what might be called the two-component theory, with the original PAS account being reserved for the terminal component of the suffix effect, as manifest at the last serial position. The preterminal component, by contrast, is assumed to be open to top-down influence. As was stated in one prominent survey (Greene, 1992), "There is a growing consensus that suffix effects at earlier positions reflects the use of particular strategies by the subjects. ... In contrast, the suffix effect at the last position is not influenced by these strategic manipulations and thus seems to be telling us something about relatively fixed structures in human memory" (p. 26).

Other findings that are, perhaps, not obviously predictable from the two-component PAS theory have nonetheless been interpreted as consistent with the theory. Thus, participant strategy has been invoked to account for the finding that rate of item presentation affects the preterminal, but not the terminal, component of the suffix effect (Balota \& Engle, 1981), whereas structural factors have been invoked to account for the finding that the delay between the last list item and the suffix affects only the terminal component of the suffix effect (Penney \& Godsell, 1993), and both strategic and structural factors have been invoked to account for the finding that the acoustic length of the suffix has opposite effects on the preterminal and terminal components of the suffix effect (Baddeley \& Hull, 1979).
In addition to the two-component PAS theory (e.g., Greene, 1992; see also Baddeley \& Hull, 1979; Balota \& Engle, 1981; Morton, 1976), other two-component accounts also have been proposed (e.g., Nairne, 1990; Penney, 1989). Although each of these theories is unique, all of them share two assumptions - namely, that (1) the preterminal suffix effect is susceptible to top-down, conceptual influence and rememberer strategy and (2) the terminal suffix effect is not susceptible to such top-down influence but, rather, is a structural effect that results from the suffix's automatically overwriting or interfering with the final item to the extent that the two are similar echoically (e.g., Greene, 1992, pp. 25-26; Penney, 1989, pp. 403-404), gesticularly (Greene, 1992, pp. 26, 39), or physically (Nairne, 1990, pp. 258-259). Thus, the conceptual (semantic) relationship between the suffix and the list items is assumed neither to influence the terminal suffix effect nor to modulate the effect of suffix delay at the terminal position (e.g., Greene, 1992; Nairne, 1990; Penney \& Godsell, 1993). And suffix effects obtained solely with static visual presentation either are predicted not to occur (e.g., Greene, 1992) or are not addressed (e.g., Nairne, 1990; Penney, 1985, p. 246).

The two-component theory remains the dominant account of the suffix effect. Indeed, of the 34 references to the theory turned up in a review of the literature, ${ }^{1}$ only 1 (Bloom \& Watkins, 1999) expressed dissent. There are, however, serious empirical challenges to the theory. Aside from a failure to replicate many of the findings on which the theory is grounded (Bloom \& Watkins, 1999), there is evidence contrary to the theory's core assumption that the terminal component of the suffix effect is immune to topdown, conceptual influence. An ambiguous suffix (wah) has a much stronger detrimental effect on recall of a final verbal list item if the suffix is framed as a verbal utterance, rather than as a nonverbal sound, such as a muted trumpet note (Ayres, Jonides, Reitman, Egan, \& Howard, 1979). Also, the effect on recall of the final item is attenuated if the item is synonymous with the suffix (Salter \& Colley, 1977). Each of these findings has been replicated (see Miles, Westley, \& Buller, 1995; Neath, Surprenant, \& Crowder, 1993; Ottley, Marcus, \& Morton, 1982) and is inconsistent with the two-component theory.

Reported here are eight new experiments that further undermine the two-component theory (e.g., Greene, 1992; see also Nairne, 1990; Penney, 1989) and, specifically, its core assumption of an immunity of the terminal component of the suffix effect to top-down, conceptual influence. Experiments 1, 2, and 3 provide further evidence that the terminal suffix effect is influenced by the semantic relationship or conceptual coherence between the suffix and the terminal list item. Experiments 4-7 show that both this relation and concomitant static visual presentation modulate the effect of suffix delay. And Experiment 8 shows that the conventional effect of separating the suffix from the list items also occurs with a static, visual mode of presentation. It is suggested that these findings, and the suffix effect literature in general, can be usefully interpreted 
in terms of perceptual grouping (see Bloom \& Watkins, 1999; see also de Gelder \& Vroomen, 1992; Kahneman, 1973; LeCompte \& Watkins, 1995), including the principles of similarity (e.g., Darwin \& Baddeley, 1974) and proximity (e.g., Frankish \& Turner, 1984).

\section{EXPERIMENT 1}

In an attempt to amplify the case that top-down, conceptually based factors can influence even the terminal suffix effect, I combined the approaches used by Salter and Colley (1977) and Ayres et al. (1979) to assess, in a novel way, whether the semantic relationship between the terminal item and the suffix would influence the suffix effect. As in early research (e.g., Morton et al., 1971; for a review see Crowder, 1976), an acoustically discrete suffix was used (see Frankish \& Turner, 1984), but as in Ayres et al.'s (1979) and Salter and Colley's (1977) studies, manipulations of context and semantic relatedness were strong. Specifically, the list items were digits, and the suffixes, presented essentially immediately after the terminal digit, were the words recall and hundred. The idea was that the participants would presumably form a stronger conceptual (semantic) union between the terminal list item and the hundred suffix (e.g., seven hundred) than between the terminal list item and the recall suffix (e.g., seven recall). At issue was whether such a conceptual manipulation would influence the suffix effect in general and the terminal suffix effect in particular. According to the two-component theory (e.g., Greene, 1992, pp. 26 and 31; see also Nairne, 1990, pp. 258-259; Penney, 1989, p. 404), the terminal suffix effect is structural and is not influenced by the conceptual (semantic) relationship between the suffix and the list items.

\section{Method}

Participants. The participants were 24 Rice University undergraduates.

Lists. The digits 1-9 were recorded on the computer in a clear male voice, and their duration was adjusted to $300 \mathrm{msec}$. Fifty-seven 9-digit lists were created, 3 lists for practice and 54 for the experiment proper. The lists were constructed by randomly ordering the digits 1-9 within the constraints that no digit was one higher or one lower in value than an immediate neighbor and that, across the 54 lists of the experiment proper, each digit occurred equally often (six times) in each of the nine list positions. The words hundred and recall were spoken in the same voice as the digits and served as suffixes. In fact, they had been recorded at the same time as the digits. Each of the suffixes, like the digits, was adjusted to a duration of $300 \mathrm{msec}$.

Design. The experiment conformed to a 3 (suffix condition) $\times 2$ (preterminal and terminal positions) design with repeated measures on both variables. Each of the three suffix conditions (no suffix, recall suffix, and hundred suffix) was represented nine times in both the first 27 lists and the last 27 lists of the experiment proper, with separate randomizations for each participant. Assignment of individual lists to suffix conditions was counterbalanced across three groups of participants, so that, overall, each list served in each condition equally often.

Procedure. The participants were tested up to 4 at a time. Instructions were shown on the computers and simultaneously read aloud by the experimenter. After practicing on three lists, the participants proceeded through the lists in the experiment at their own pace, with lists being presented from their computers via headphones.

The participants initiated each list by clicking a "start" button. After a 500-msec delay, the digits were presented via the headphones at a $900-\mathrm{msec}$ onset-to-onset rate. Following the last digit, the participants heard nothing, the suffix recall, or the suffix hundred. The onset of the suffix followed the offset of the last digit by $17 \mathrm{msec}$. Immediately following the suffix (and hence, $317 \mathrm{msec}$ after offset of the last digit), the participants were presented with nine position (response) markers. In the no-suffix condition, the position markers also appeared $317 \mathrm{msec}$ after the offset of the last digit, but the interval between the last digit and presentation of the position markers was unfilled. Once the position markers had appeared, the participants attempted to type the digits, from left to right, in their order of presentation, using the hyphen key for each digit they failed to recall. The responses appeared in a size 24 Monaco font above the position markers. At any point during recall, the last item typed could be erased by pressing the delete key; earlier responses could not be changed. The participants responded at their own rate and signaled trial completion by clicking an "OK" button.

\section{Results}

Figure 1 shows the serial recall function for each suffix condition. Most important, the hundred suffix effect was smaller than the recall suffix effect, especially at the terminal position.

Following Penney (1985) and Bloom and Watkins (1999), statistical analyses for all eight experiments in the present report focused on the final four positions, of which the three prior to the last were referred to as preterminal positions (or collectively, as the preterminal position) and the last as the terminal position. All $t$ tests were two-tailed. The relevant findings of Experiment 1 can be stated in five points. ${ }^{2}$

1. With the data averaged across the last four positions, mean probability of recall was higher in the no-suffix condition (.72) than in both the recall suffix condition (.48) $[t(23)=9.14, p=.000]$ and the hundred suffix condition (.55) $[t(23)=7.57, p=.000] . .^{3}$

2 . With the data averaged across the last four positions, the hundred suffix effect (.17) was smaller than the recall suffix effect (.24) $[t(23)=2.47, p=.02]$.

3 . For the three preterminal positions, although the hundred suffix effect (.14) was somewhat smaller than the recall suffix effect (.19), the difference was not entirely convincing $[t(23)=1.80, p=.08]$.

4. The terminal suffix effect was smaller following the hundred suffix (.25) than following the recall suffix (.39) to an extent unlikely to have arisen by chance $[t(23)=$ $2.96, p=.007]$.

5. A 3 (suffix condition) $\times 2$ (position) ANOVA with repeated measures on both variables revealed a convincing interaction between suffix condition and position $\left[F(2,46)=14.88, M S_{\mathrm{e}}=0.008, p=.000\right]$. Of particular interest is that the difference in the recall and hundred suffix effects was greater at the terminal position (.14) than at the preterminal positions (.05). An ANOVA for just the recall and hundred data showed that the difference between these suffix effects, as expressed in the suffix $X$ 


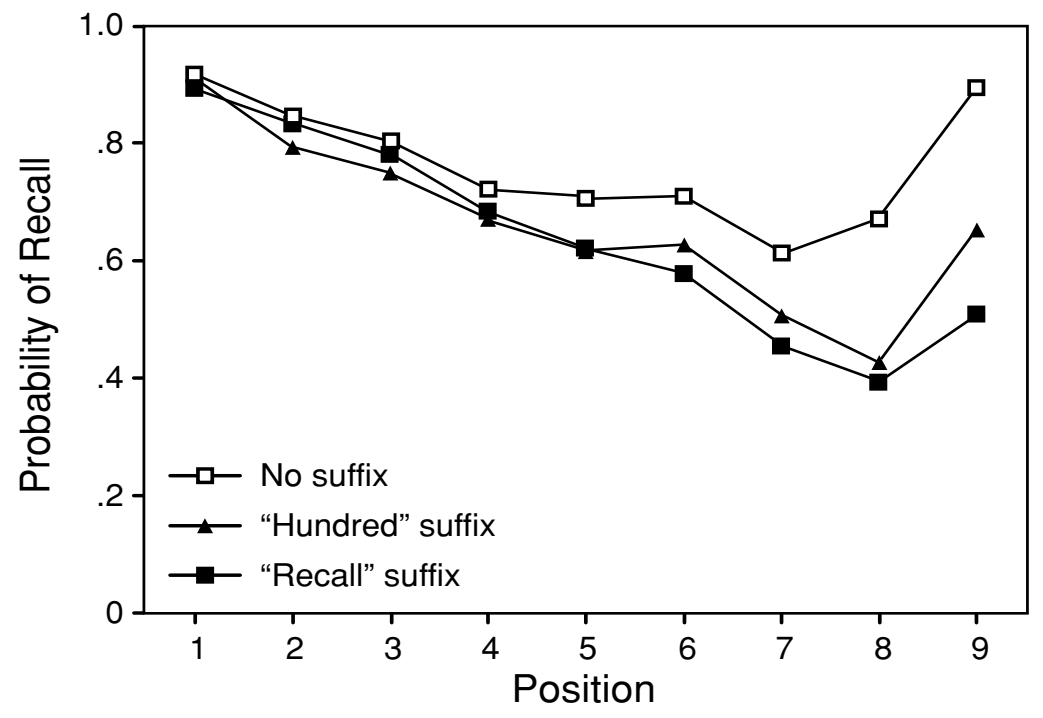

Figure 1. Probability of recall as a function of within-list position and suffix condition (Experiment 1).

position interaction, was unlikely to have arisen by chance $\left[F(1,23)=7.01, M S_{\mathrm{e}}=0.008, p=.01\right]$. This interaction needs to be interpreted with caution, however, since the proportional decrement in the suffix effect obtained with the hundred suffix rounded to $36 \%$ at both the preterminal and the terminal positions (see Figure 1).

Changing the semantic identity of the suffix from recall to hundred had a less-than-convincing influence on the preterminal component of the suffix effect, but it clearly attenuated the terminal component. This finding, like those obtained by Salter and Colley (1977) and Ayres et al. (1979), suggests that the terminal suffix effect is influenced by the way the participants conceptualize the suffix in relation to the terminal list item.

Moreover, it would appear unlikely that the present findings are the result of undue attention being given to the terminal item (see Salter \& Colley, 1977). Thus, assuming a limited recall capacity (e.g., Crowder, 1976), any gain in recall of the terminal item would be expected to be offset by reduced recall of the preterminal items. But as can be seen in Figure 1, the data provide little evidence for this possibility.

\section{EXPERIMENT 2}

Experiment 2 was intended as a check on the primary conclusion drawn from Experiment 1 -namely, that the attenuation of the terminal suffix effect when hundred served as the suffix was due to the participants' forming a stronger semantic unification of the suffix and the terminal list item. It was identical to Experiment 1, except that hundred and recall were replaced by dredhun and callre. Thus, the component sounds of the suffixes remained the same, and just their order was changed. According to the semantic grouping interpretation, the attenuation of the terminal suffix effect should not extend to this experiment, because both suffixes are meaningless and, so, should not differ in their semantic relation to the terminal list item.

\section{Method}

Participants. The participants were 24 Rice University undergraduates.

Lists. The digit utterances and list construction were exactly the same as those in Experiment 1. The suffix utterances were those used in Experiment 1, except that they were spliced and reconfigured to be meaningless (callre and dredhun) and, therefore, were semantically unrelated to the digits, although containing the same acoustic information. The suffixes, like the digits, remained $300 \mathrm{msec}$ in duration.

Design. The experiment conformed to a 3 (suffix condition) $\times 2$ (preterminal and terminal positions) design with repeated measures on both variables. In the experiment proper, the three suffix conditions (no suffix, callre suffix, and dredhun suffix) occurred equally often and in random order in both the first 27 lists and the last 27 lists, with separate randomizations for each participant. Assignment of individual lists to suffix conditions was counterbalanced across three groups of participants, so that, overall, each list served in each condition equally often.

Procedure. The procedure was identical to that in Experiment 1 .

\section{Results}

Figure 2 shows the serial recall function for each suffix condition. Importantly, the dredhun suffix was no less detrimental to recall at the terminal position than was the callre suffix. The relevant findings can be stated in five points. ${ }^{4}$

1. With the data averaged across the last four positions, mean probability of recall was higher in the no-suffix condition (.60) than in both the callre suffix condition (.43) $[t(23)=8.21, p=.000]$ and the dredhun suffix condition (.40) $[t(23)=8.76, p=.000]$.

2 . With the data averaged across the last four positions, the callre suffix effect (.17) was, if anything, smaller than the dredhun suffix effect $(.20)[t(23)=1.88, p=.07]$. 


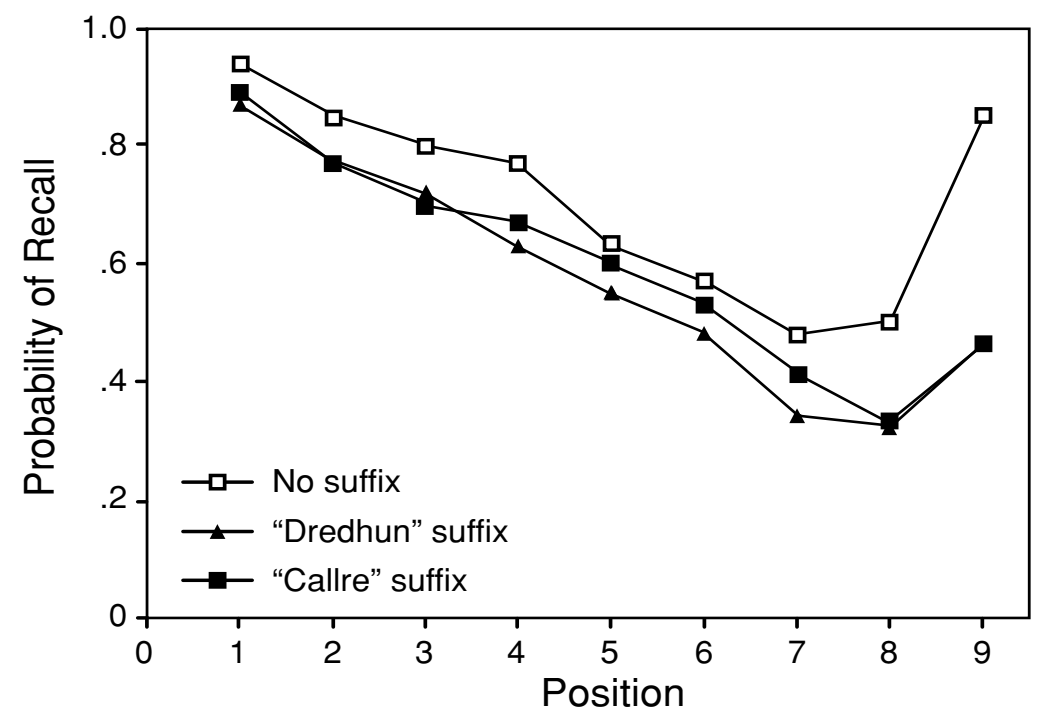

Figure 2. Probability of recall as a function of within-list position and suffix condition (Experiment 2).

3. For the three preterminal positions, the callre suffix effect (.10) was somewhat smaller than the dredhun suffix effect $(.14)[t(23)=2.22, p=.04]$. Even if additional research were to show this effect to be real, the fact that it is mediated almost entirely by the third and fourth positions from the end of the list, rather than the second from the end of the list, undermines its relevance to present purposes.

4. The terminal suffix effect was virtually identical in the callre and the dredhun conditions [rounding to .46 in both cases; $t(23)=0.22, p=.83]$.

5. A 3 (suffix condition) $\times 2$ (position) ANOVA with repeated measures on both variables revealed a convincing interaction between suffix condition and position $\left[F(2,46)=28.76, M S_{\mathrm{e}}=0.010, p=.000\right]$. Although the difference in the callre and the dredhun suffix effects was slightly less at the terminal position (.00) than at the preterminal positions (.04), an ANOVA for just the callre and dredhun data showed that the difference between these suffix effects, as expressed in the suffix $\times$ position interaction, was unconvincing $\left[F(1,23)=1.29, M S_{\mathrm{e}}=0.007\right.$, $p=.27]$.

Whereas the terminal suffix effect for digit lists was smaller with a hundred suffix than with a recall suffix (Experiment 1), the terminal suffix effect was not smaller with a dredhun suffix than with a callre suffix (Experiment 2). This finding suggests that the attenuation of the terminal hundred suffix effect, relative to the terminal recall suffix effect (Experiment 1), was not the result of a fortuitous difference in the acoustical components of hundred and recall. By the same token, it reinforces the conclusion that contrary to the two-component theory (e.g., Greene, 1992; see also Nairne, 1990; Penney, 1989), the terminal suffix effect is susceptible to the conceptual coherence (semantic relation) between the suffix and the last item of the list.

\section{EXPERIMENT 3}

Experiments 1 and 2 provide strong evidence that even the terminal component of the suffix effect is subject to top-down influence. Such evidence is contrary to the core assumption of overwriting theories in general and of the two-component theory in particular-namely, that the terminal suffix effect is immune to conceptually based influences. It could be countered, however, that it is not necessarily contrary to a watered-down version of such theories, whereby recall of the last few items of a list (or in the case of the two-component theory, the terminal item) is the product of postcategorical, as well as precategorical, memory. Given the patently obvious fact that all items are perceived directly upon presentation, all of them must be subject to postcategorical processing, in which case it is not unreasonable to assume that they will endure to some extent in a postcategorical memory (see Craik \& Lockhart, 1972; Crowder, 1976). If this much is conceded, the critical findings of Experiment 1 could be explained as a von Restorff (1933) effect. The von Restorff, or isolation, effect is the finding that if all list items but one are similar, memory for the different item will be enhanced (see, e.g., Fabiani \& Donchin, 1995; Hunt, 1995; von Restorff, 1933; Wallace, 1965). Thus, in Experiment 1, any conceptual (postcategorical) unification of the hundred suffix with the terminal item would result in a subjective terminal item that was conceptually distinct from the other list items and, perhaps, could be comparatively well recalled for just this reason. In other words, the two-component and other overwriting theories would apply to just the structural (precategorical) contribution to memory and, thus, be unaffected by any conceptual unification of the suffix with the terminal list item.

The purpose of Experiment 3 was twofold. First, it provided an opportunity to replicate the Experiment 1 finding 
that promoting conceptual (semantic) coherence between the suffix and the terminal list item attenuated the suffix effect. Second, it provided a test of the von Restorff (1933) explanation of this finding. If the attenuation of the terminal suffix effect is due to the conceptual distinctiveness of the functional terminal item (e.g., seven hundred), it should not occur if hundred followed not just the terminal item, but every list item. Thus, to the three conditions in Experiment 1, Experiment 3 added a through-list hundred condition, so that a single hundred suffix followed each of the nine list items.

\section{Method}

Participants. The participants were 24 Rice University undergraduates.

Lists. The digit and suffix utterances were the same as those used in Experiment 1. Of 76 nine-digit lists that were created, 4 were used for practice and 72 for the experiment proper. List construction was the same as that in Experiment 1. In the experiment proper, each digit occurred on eight occasions in each of the nine list positions.

Design. The experiment conformed to a 4 (suffix condition) $\times 2$ (preterminal and terminal positions) design with repeated measures on both variables. Each of the four suffix conditions (no suffix, recall suffix, hundred suffix, and through-list hundred suffix) was represented nine times in random order in both the first 36 lists and the last 36 lists of the experiment proper, with separate randomizations for each participant. Assignment of individual lists to suffix conditions was counterbalanced across four groups of participants, so that, overall, each list served in each condition equally often.

Procedure. The procedure was identical to that in Experiment 1, except that, to accommodate the added (through-list hundred) suffix condition, the number of lists was increased by one third.

\section{Results}

Figure 3 shows the serial recall function for each suffix condition. Relative to the recall suffix, the hundred suffix again attenuated the detrimental effect of the suffix at the terminal position. Moreover, a similar attenuation also occurred when hundred followed every list item, rather than just the last. The relevant findings can be stated in five points. ${ }^{5}$

1. With the data averaged across the last four positions, mean probability of recall was higher in the no-suffix condition (.67) than in the recall suffix condition (.51) $[t(23)=6.76, p=.000]$, the hundred suffix condition (.53) $[t(23)=5.84, p=.000]$, and the through-list hundred suffix condition (.50) $[t(23)=7.07, p=.000]$.

2 . With the data averaged across the last four positions, the recall suffix effect (.16) did not differ from the hundred suffix effect $(.14)[t(23)=1.60, p=.12]$ or the through-list hundred suffix effect (.17) $[t(23)=0.30, p=$ .77]. The hundred suffix effect differed, albeit not entirely convincingly, from the through-list hundred suffix effect $[t(23)=1.88, p=.07]$.

3 . For the three preterminal positions, the recall suffix effect (.11) did not differ from the hundred suffix effect (.11) $[t(23)=0.24, p=.82]$, nor did it differ convincingly from the through-list hundred suffix effect (.15) $[t(23)=1.68, p=.11]$. The hundred and through-list hundred suffix effects did not differ discernibly $[t(23)=$ $1.77, p=.09]$.

4. At the terminal position, the recall suffix effect (.33) was larger than the hundred suffix effect $(.21)[t(23)=$ $4.24, p=.0003]$ and the through-list hundred suffix effect (.23) $[t(23)=3.92, p=.0007]$. The hundred suffix effect was not discernibly different from the through-list hundred suffix effect $[t(23)=0.79, p=.44]$.

5. A 4 (suffix condition) $\times 2$ (position) ANOVA with repeated measures on both variables revealed a convincing interaction between suffix condition and position $\left[F(3,69)=14.40, M S_{\mathrm{e}}=0.008, p=.007\right]$. Of particular interest are three findings. First, relative to the recall condition, the attenuation of the suffix effect in the hundred condition was more pronounced at the terminal position (.12) than at the preterminal positions (.00). An ANOVA

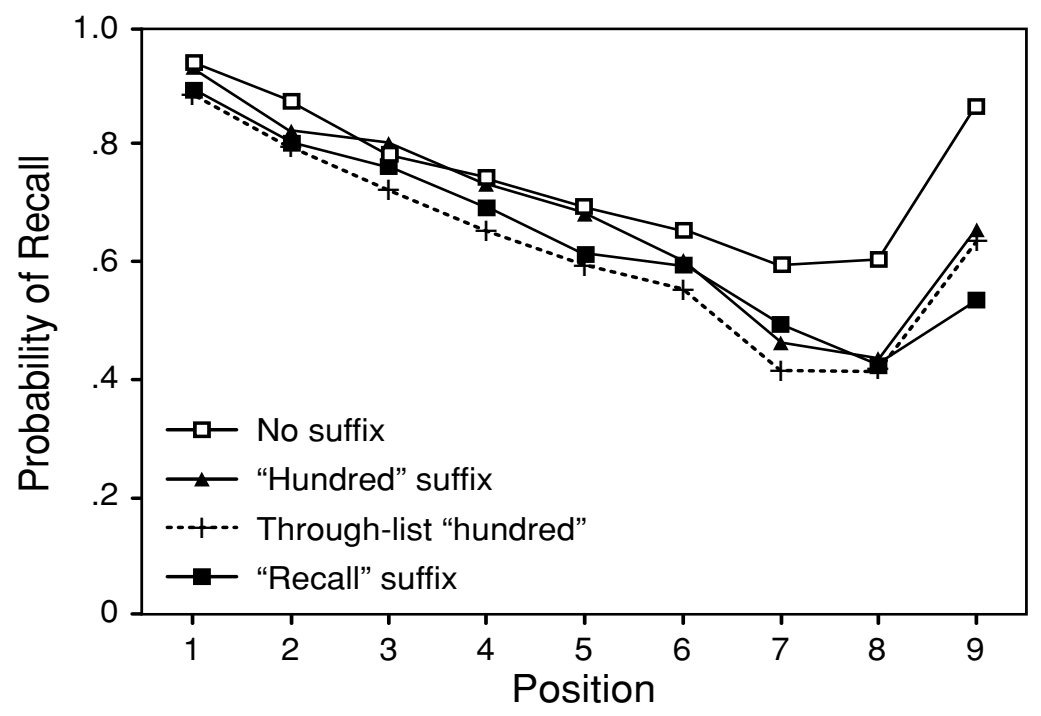

Figure 3. Probability of recall as a function of within-list position and suffix condition (Experiment 3). 
for just the recall and hundred data showed that the difference between these suffix effects, as expressed in the suffix $\times$ position interaction, was unlikely to have arisen by chance $\left[F(1,23)=14.44, M S_{\mathrm{e}}=0.007, p=.001\right]$. Second, relative to the recall condition, the attenuation of the suffix effect in the through-list hundred condition was more pronounced at the terminal position (.10) than at the preterminal positions (-.04). An ANOVA for just the recall and the through-list hundred data showed that this difference, as expressed in the suffix $\times$ position interaction, was also unlikely to have arisen by chance $\left[F(1,23)=24.17, M S_{\mathrm{e}}=0.006, p=.000\right]$. Finally, relative to the through-list hundred condition, the attenuation of the suffix effect in the hundred condition was slightly less pronounced at the terminal position (.02) than at the preterminal positions (.04). An ANOVA for just the through-list hundred and the hundred data showed that this difference, as expressed in the suffix $\times$ position interaction, could easily have arisen by chance $[F(1,23)=$ $\left.0.67, M S_{\mathrm{e}}=0.005, p=.42\right]$.

In short, the results of this experiment replicated the two critical findings of Experiment 1. First, changing the suffix from recall to hundred had no reliable influence at the preterminal positions but did attenuate the terminal suffix effect. Second, this finding appears not to have been the result of the participants' giving extra attention (rehearsal, etc.) to the last item at the expense of the preceding items (see Salter \& Colley, 1977). In fact, as can be seen in Figure 3, performance in the hundred condition was numerically superior to that in the recall condition at eight of the nine positions, the average probability of recall for all nine positions being .68 in the hundred condition and .64 in the recall condition.

The inclusion of a through-list hundred condition, in which hundred occurred after each of the nine digits, allowed evaluation of a von Restorff (1933) interpretation of the attenuation of the terminal suffix effect in the hundred suffix condition. The terminal suffix effect in the throughlist condition was similar to that in the hundred condition and smaller than that in the recall condition, implying that the observed influence of semantic relatedness between the terminal item and the suffix was not the result of the functional terminal list item's (e.g., seven hundred) being remembered better because it was distinctive, relative to the other list items. This pattern of findings is inconsistent with the two-component theory (e.g., Greene, 1992; see also Nairne, 1990; Penney, 1989) but is consistent with the idea that the terminal suffix effect can be influenced by the conceptual relation or coherence between the suffix and the final list item.

\section{EXPERIMENT 4}

Experiments 4-7 investigated suffix delay. Previous research has shown that delaying the suffix serves to reduce the suffix effect - most notably (Bloom \& Watkins, 1999; Crowder, 1969, 1971; Frankish \& Turner, 1984), and sometimes exclusively (Penney \& Godsell, 1993), at the terminal position. This finding has been interpreted in terms of the overwriting of time-dependent structural information (e.g., Greene, 1992; see also Nairne, 1990; Penney, 1989) and, therefore, as consistent with the two-component theory (e.g., Penney \& Godsell, 1993). The results of Experiments 1 and 3 raise the intriguing possibility that this finding may not hold over all conditions. Specifically, these experiments showed that the suffix effect and, particularly, its terminal component can be reduced when the suffix can be semantically integrated with the terminal list item to form a conceptual unit. Perhaps, therefore, the detrimental increment in the effect of a suffix when its presentation is hastened might not hold with the hundred suffix, for it would tend to be opposed by the effect of semantic coupling between the terminal item and an immediate suffix. In short, with hundred, rather than, say, recall or zero, as the suffix, the typical attenuation of the suffix effect that is brought about by delaying the suffix would be less apparent, eliminated, or even reversed. The purpose of Experiment 4 was to explore this possibility.

\section{Method}

Participants. The participants were 72 Rice University undergraduates.

Lists. The to-be-remembered items and the suffix were the digit and hundred recordings used in Experiment 1. Fifty-four 9-digit lists were constructed in the same manner as that described in Experiment 1 . Three additional lists were constructed for practice.

Design. The experiment conformed to a 3 (suffix condition) $\times$ 2 (preterminal and terminal positions) design with repeated measures on both variables. For the control condition, the last item of the list was followed by silence; for the immediate suffix condition, offset of the last list item was followed by the word hundred with a pause of a mere $17 \mathrm{msec}$; and for the delayed suffix condition, the word hundred followed the offset of the last list item only after a noticeable delay. Actually, the duration of this delay was varied: For half of the participants, it was $600 \mathrm{msec}$ (putting the suffix in rhythm with the list items), and for the other half of the participants, it was $1,500 \mathrm{msec}$. With a typical suffix (e.g., zero), the delayed suffix condition attenuates the suffix effect only if the delay exceeds the interstimulus interval of the list items; if the delay is equal to or less than the interstimulus interval, the difference in suffix effects is, at best, quite small (see, e.g., Frankish \& Turner, 1984). Thus, it seemed reasonable to assess whether the influence of a novel hundred suffix would similarly depend on the length of the suffix delay. As it happens, the findings did not differ discernibly between the two groups of participants, and in the interest of both brevity and clarity, the data were combined across the two groups. Assignment of individual lists to suffix condition was counterbalanced across three groups of participants, so that, overall, each list served equally often in each suffix condition.

Procedure. Apart from the details of suffix presentation, the procedure was the same as that in Experiment 1. For half of the participants, in all three conditions (no, immediate, and short-delayed suffix), digits were presented at a 900 -msec onset-to-onset rate, and the nine position (response) markers were presented $900 \mathrm{msec}$ following the offset of the terminal list item. For the other half of the participants, in all three conditions (no, immediate, and longdelayed suffix), the digits were also presented at a 900-msec onset-toonset rate, but the nine response markers were presented $1,800 \mathrm{msec}$ following the offset of the terminal list item. Note that for the respective delayed suffix conditions, this timing ensured that onset of the response markers coincided with the offset of the delayed suffix. The 
order of list presentation and, hence, of the three suffix conditions was separately randomized for each participant.

\section{Results}

Figure 4 shows the serial recall function for each suffix condition. Contrary to previous findings (e.g., Crowder, 1971; Frankish \& Turner, 1984; Penney \& Godsell, 1993), delaying the suffix failed to mitigate the terminal suffix effect. The relevant findings are as follows. ${ }^{6}$

1. With the data averaged across the last four positions, mean probability of recall was higher in the no-suffix condition (.63) than in both the immediate suffix condition $(.46)[t(71)=12.20, p=.000]$ and the delayed suffix condition (.49) $[t(71)=10.87, p=.000]$.

2 . With the data averaged across the last four positions, the delayed suffix effect (.14) was somewhat smaller than the immediate suffix effect $(.17)[t(71)=1.96, p=.05]$.

3 . For the three preterminal positions, the effect of a delayed suffix (.11) was smaller than that of an immediate suffix $(.15)[t(71)=2.96, p=.004]$.

4. The terminal suffix effect was virtually identical in the delayed and the immediate suffix conditions [rounding to .24 in both instances; $t(71)=0.17, p=.87]$.

5. A 3 (suffix condition) $\times 2$ (position) ANOVA with repeated measures on both variables revealed a convincing interaction between suffix condition and position $\left[F(2,142)=17.91, M S_{\mathrm{e}}=0.008, p=.000\right]$. The difference between the immediate and the delayed suffix effects was larger at the preterminal positions (.04) than at the terminal position (.00). An ANOVA for just the immediate suffix and delayed suffix data showed that the difference between these suffix effects, as expressed in the delay $\times$ position interaction, was not entirely convincing $\left[F(1,71)=3.33, M S_{\mathrm{e}}=0.008, p=.07\right]$.

In short, this experiment showed that delaying a hundred suffix attenuated its effect only slightly and, more important, that such attenuation as did occur was localized at the preterminal positions. This finding is thus entirely contrary to the assumption that the effect of suffix delay is restricted to the terminal position (e.g., Penney \& Godsell, 1993). Moreover, this finding undermines the core assumption of the two-component theory (e.g., Greene, 1992; see also Nairne, 1990; Penney, 1989)—namely, that delaying a suffix, regardless of its conceptual (semantic) relationship to the list items, attenuates the effect of timedependent, structural overwriting and diminishes the terminal suffix effect.

\section{EXPERIMENT 5}

The purpose of Experiment 5 was to see whether a conventional effect of suffix delay would occur with a procedure identical to that in Experiment 4, except for the substitution of a standard suffix. Zero was presently used as the standard suffix because (1) it is perhaps the quintessential suffix used in the literature and provides a wellestablished reference point, (2) it increases the generalizability of the present findings (in Experiments 1-3, a recall suffix was used), and (3) it provides the opportunity to assess the influence of two types of 0 suffixes - namely, hundred (00) and zero (0).

To the extent that the findings of Experiment 4 reflected the strong conceptual relation between the suffix and the terminal list item (e.g., seven hundred), the findings of Experiment 5 should be different. Presumably, the effect of delay should be most pronounced at, or confined to, the terminal position (e.g., Crowder, 1971; Frankish \& Turner, 1984; Penney \& Godsell, 1993).

\section{Method}

Participants. The participants were 33 Rice University undergraduates.

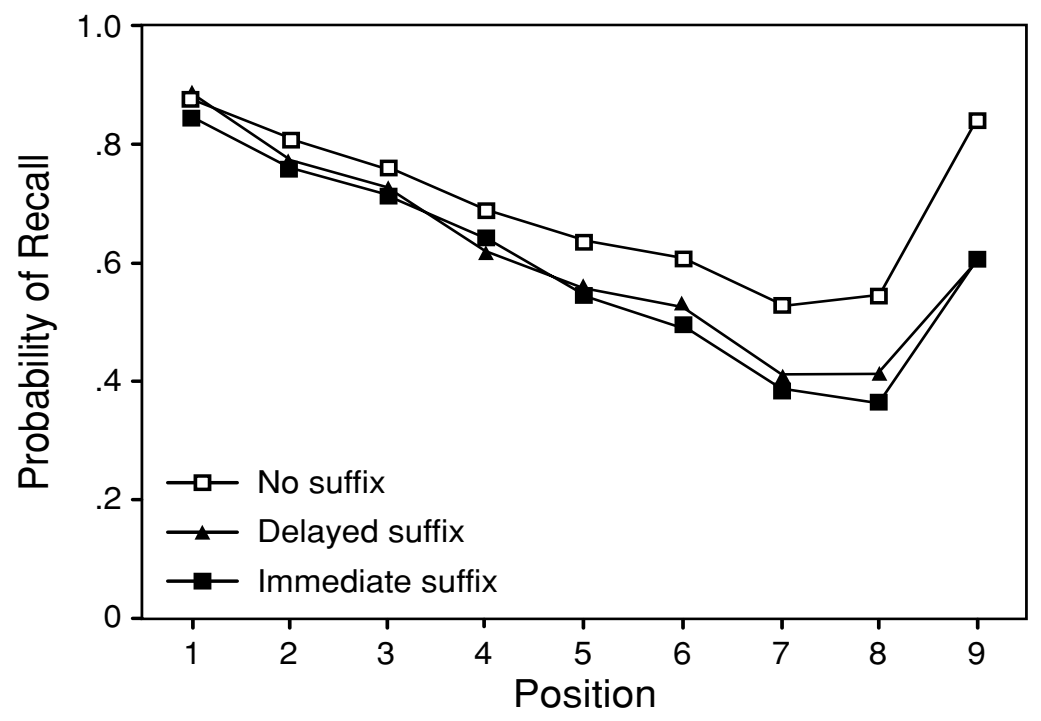

Figure 4. Probability of recall as a function of within-list position and suffix condition (Experiment 4). 
Lists. The stimuli were the recordings used in Experiment 4, with the exception that the suffix word hundred was replaced by zero. The zero was recorded at the same time as the stimuli used in Experiment 1 (and hence, Experiment 4) and, like the list items, was adjusted to a $300-$ msec duration.

Design and Procedure. The design and procedure were the same as those in Experiment 4, with one exception. Because, with a typical suffix (e.g., zero), delaying the suffix serves to attenuate its effect only if the delay exceeds the interval separating the list items (e.g., Frankish \& Turner, 1984), the 1,500-msec suffix delay was used in the delayed suffix condition for all the participants.

\section{Results}

Figure 5 shows the serial recall function for each suffix condition. Consistent with previous research (e.g., Crowder, 1971; Frankish \& Turner, 1984), delaying a zero suffix attenuated the suffix effect, with the attenuation being greatest at the terminal position. The relevant findings can be stated in five points (see also note 6).

1. With the data averaged across the last four positions, mean probability of recall was higher in the no-suffix condition (.66) than in both the immediate suffix condition (.49) $[t(32)=9.65, p=.000]$ and the delayed suffix condition $(.52)[t(32)=8.03, p=.000]$.

2 . With the data averaged across the last four positions, the delayed suffix effect (.14) was smaller than the immediate suffix effect $(.17)[t(32)=2.22, p=.03]$.

3 . For the three preterminal positions, the delayed suffix effect (.10) was not discernibly smaller than the immediate suffix effect $(.12)[t(32)=1.13, p=.27]$.

4. The terminal suffix effect was clearly smaller in the delayed suffix condition (.24) than in the immediate suffix condition $(.32)[t(32)=2.68, p=.01]$.

5. A 3 (suffix condition) $\times 2$ (position) ANOVA with repeated measures on both variables revealed a convincing interaction between suffix condition and position $\left[F(2,64)=16.88, M S_{\mathrm{e}}=0.010, p=.000\right]$. The difference in the delayed and the immediate suffix effects was greater at the terminal position (.08) than at the preterminal positions (.02). As expressed in the delay $\times$ position interaction of an ANOVA for just the immediate suffix and delayed suffix data, this difference was not entirely convincing $\left[F(1,32)=3.71, M S_{\mathrm{e}}=0.009, p=.06\right]$. When account is taken of the prediction that the delayed suffix effect would be smaller than the immediate suffix effect-as opposed to merely different_-it becomes a little more convincing $(p=.03)$.

In short, the conventional finding that delaying a standard suffix reduces its effect at the terminal list position was replicated. Of more particular importance was the difference in the pattern of results between this experiment and Experiment 4. Whereas in Experiment 4 the effect of suffix delay was restricted to the preterminal position, in Experiment 5 the effect of delay increased systematically across the last four positions. Since the only difference between Experiments 4 and 5 was in the nature of the suffix (hundred vs. zero), it seems likely that the effect of suffix delay in Experiment 4 was moderated by the semantic relation between the suffix and the terminal list item. This pattern of findings is not consistent with the two-component theory (e.g., Greene, 1992; see also Nairne, 1990; Penney \& Godsell, 1993).

\section{EXPERIMENT 6}

The elimination of the conventional effect of suffix delay at the terminal position in Experiment 4 raises the intriguing possibility that if the conceptual coherence between the immediate suffix and the terminal list item was even stronger than that in Experiment 4, the conventional effect of suffix delay on recall of the terminal list item might even be reversed.

According to the two-component theory (e.g., Greene, 1992), the terminal component of the suffix effect has a structural (precategorical) locus, and given that static vi-

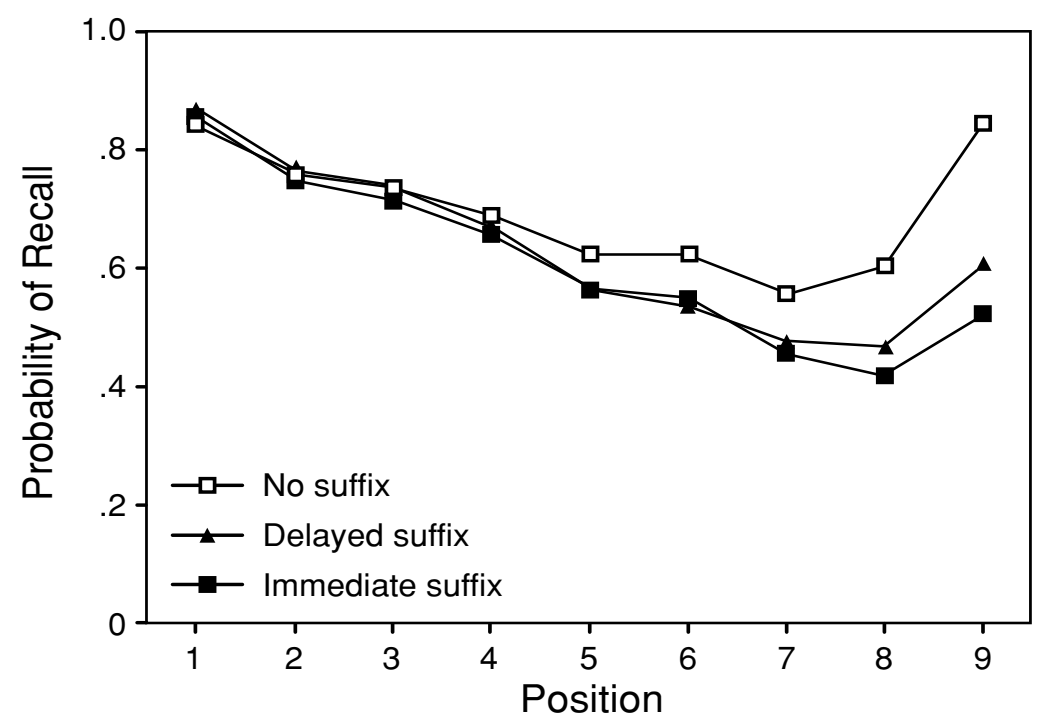

Figure 5. Probability of recall as a function of within-list position and suffix condition (Experiment 5). 
sual information and auditory information do not "meet" until the categorical level (Crowder, 1976, p. 59), the auditory suffix effect should not be affected by simultaneous static visual presentation (see Crowder, 1976; Crowder \& Morton, 1969; Greene, 1992; Greene \& Crowder, 1984b). And indeed, for all intents and purposes, bimodal presentation has been found to yield the same pattern of results as purely auditory presentation (e.g., Crowder, 1970; see also Crowder, 1976; Greene \& Crowder, 1984b; Greene et al., 1988; Nairne \& Walters, 1983).

On the other hand, the conceptual (postcategorical) effects presently obtained in Experiments 1-5, as well as those in certain previous studies (Ayres et al., 1979; Salter \& Colley, 1977), suggest the possibility that presenting the hundred suffix and list digits with concomitant static visual information could further enhance the semantic relationship between the terminal item and an immediate suffix. If it is assumed that such enhanced conceptual integration would dissipate with suffix delay, the delayed suffix effect could end up larger than the immediate suffix effect. Such a finding would clearly be at variance with the notion, at the core of the two-component theory (e.g., Greene, 1992; see also Nairne, 1990; Penney, 1989; Penney \& Godsell, 1993), that the terminal suffix effect is solely the product of passive, time-dependent, structural overwriting. Experiment 6 was designed to evaluate this possibility.

\section{Method}

Participants. The participants were 72 Rice University undergraduates.

Lists. The stimuli were the same as those used in Experiment 4.

Design. The design was the same as that in Experiment 4. As before, there was no discernible difference between the data for the two participant groups (i.e., between the effects of 600- and 1,500-msec auditory suffix delays in the delayed suffix conditions), and only the combined data will be reported.
Procedure. The procedure was the same as that in Experiment 4, with the exception that all the stimuli were shown in the center of the monitor in size 72 Courier font at the same time that they were spoken. More precisely, the visual and auditory presentation began at the same instant, but whereas the auditory version lasted just $300 \mathrm{msec}$, the visual version lasted $650 \mathrm{msec}$. In the immediate suffix condition, the auditory characteristics of Experiment 4 were retained, with just $17 \mathrm{msec}$ separating the offset of the last item from the onset of the suffix. Visually, the last item (e.g., 7) and the suffix (00) were presented simultaneously (i.e., as 700) at the spoken onset of the last item. In the delayed suffix condition, the auditory characteristics of Experiment 4 were retained with, depending on participant group, either a 600 - or a 1,500-msec interval separating the offset of the last item from the onset of the suffix. Visually, the last item (e.g., 7) and the suffix (00) were presented separately-namely, at the spoken onset of the last item and the spoken onset of the suffix, respectively. The visual suffix (00) was presented just to the right of where the last digit had been presented, so that the spatial relationship between the suffix and the last list item was the same in the immediate and the delayed suffix conditions.

Thus, for half of the participants, in all three conditions (no, immediate, and short-delayed suffix), digits were presented at a $900-\mathrm{msec}$ onset-to-onset rate, and the nine response markers were presented $1,250 \mathrm{msec}$ following the auditory offset of the terminal list item. For the other half of the participants, in all three conditions (no, immediate, and long-delayed suffix), digits were also presented at a 900-msec onset-to-onset rate, but the nine response markers were presented $2,150 \mathrm{msec}$ following the auditory offset of the terminal list item. Note that for the respective delayed suffix conditions, this timing ensured that onset of the nine response markers coincided with the visual offset of the delayed suffix.

\section{Results}

Figure 6 shows the serial recall function for each suffix condition. In a reversal of its characteristic attenuating influence, delaying a suffix actually enlarged the terminal suffix effect. The relevant findings are as follows (see also note 6).

1. With the data averaged across the last four positions, mean probability of recall was higher in the no-suffix con-

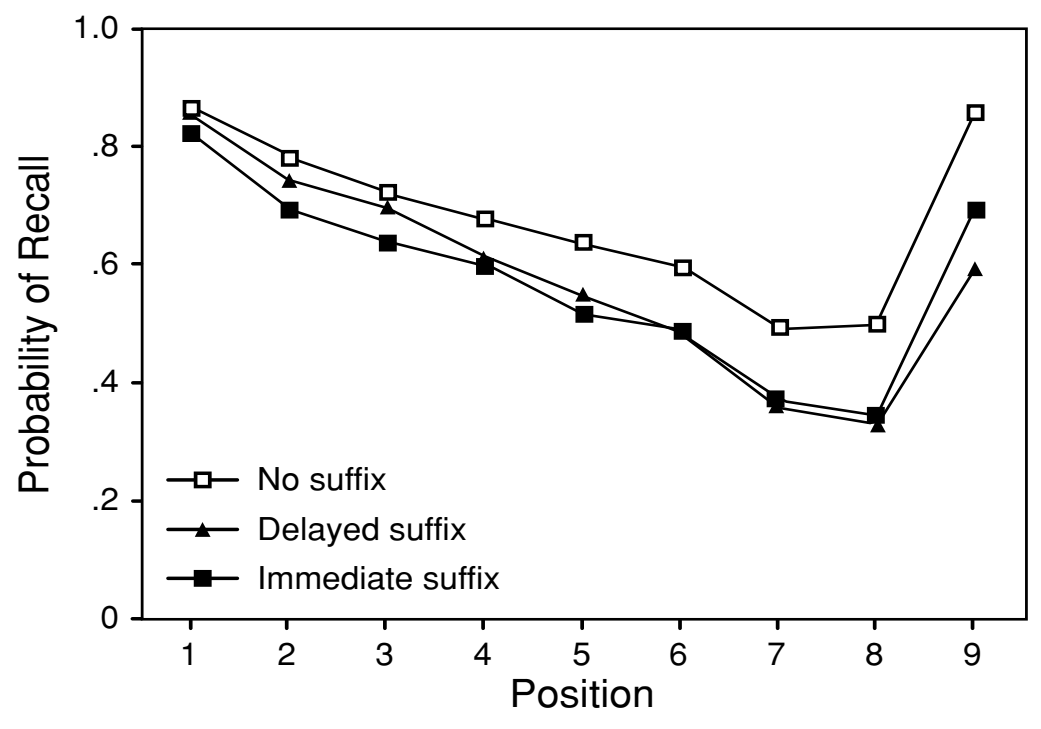

Figure 6. Probability of recall as a function of within-list position and suffix condition (Experiment 6). 
dition (.61) than in both the immediate suffix condition (.48) $[t(71)=12.25, p=.000]$ and the delayed suffix condition (.44) $[t(71)=12.96, p=.000]$.

2 . With the data averaged across the last four positions, the delayed suffix effect (.17) was modestly larger than the immediate suffix effect $(.13)[t(71)=2.44, p=.02]$.

3 . For the three preterminal positions, the immediate (.13) and the delayed (.14) suffix effects differed very little $[t(71)=0.70, p=.49]$.

4. The terminal suffix effect was larger in the delayed suffix condition (.26) than in the immediate suffix condition (.16). The difference was unlikely to have arisen by chance $[t(71)=4.76, p=.000]$.

5. A 3 (suffix condition) $\times 2$ (position) ANOVA with repeated measures on both variables revealed a convincing interaction between suffix condition and position $\left[F(2,142)=24.23, M S_{\mathrm{e}}=0.006, p=.000\right]$. Of particular interest is that the difference in the immediate and the delayed suffix effects was larger at the terminal position (.10) than at the preterminal (.01) positions. An ANOVA for just the immediate suffix and delayed suffix data showed that the difference between these suffix effects, as expressed in the delay $\times$ position interaction, was unlikely to have arisen by chance $\left[F(1,71)=20.11, M S_{\mathrm{e}}=0.008, p=.000\right]$.

In summary, the use of a hundred suffix, together with concomitant static visual presentation, reversed the typical effect of suffix delay (e.g., Experiment 5), so that delay enlarged the suffix effect, at least at the terminal position. This finding is predicted neither by bottom-up overwriting accounts of the suffix effect in general (see Crowder \& Morton, 1969; Frankish \& Turner, 1984) nor by the two-component theory in particular (e.g., Greene, 1992; see also Nairne, 1990; Penney \& Godsell, 1993). Rather, it suggests that the terminal suffix effect depends on the way participants conceptualize the relation between the suffix and the terminal item.

\section{EXPERIMENT 7}

Experiment 7 was intended as a check on the primary conclusion drawn from Experiment 6-namely, that the reversal of the typical effect of suffix delay was, indeed, due to some sort of semantic unification of the suffix and the terminal list item. There is, as it happens, an alternative explanation. Because the spoken onset of the last list item coincided with the visual onset of both the last item and the suffix in the immediate suffix condition, the participants had (a 317-msec) visual forewarning of the spoken suffix that was not available in the delayed suffix condition. It is conceivable that this forewarning enabled the participants to attend to the last item and ignore the suffix in a way that was not possible in the delayed suffix condition. Moreover, assuming a limited memory capacity (see, e.g., Crowder, 1976), such an attentional deployment to the end of the list could account for the finding in Experiment 6 of modestly lower recall across the first three positions in the immediate condition (.69), in comparison with the delayed condition $(.74)[t(71)=2.71, p=.01]$.
Experiment 7 was designed to evaluate this alternative interpretation of the results of Experiment 6. It was identical to Experiment 6, except for the spatial configuration of the visual component of the terminal list item and suffix. At issue was whether reconfiguring the visual aspects of the presentation of the final list digit and the suffix would affect the immediate suffix effect and, thus, modulate the influence of suffix delay found in Experiment 6. According to the semantic grouping interpretation, if the visual presentation of the immediate suffix and the last list item were presented in an unfamiliar and relatively meaningless spatial relation, the visual information would do little to promote conceptual unification of the suffix and the last list item, and so the effect of suffix delay should be similar to that found with purely auditory presentation, as in Experiment 4. In other words, it was predicted that in this experiment, the effect of a hundred suffix at the terminal position would be essentially invariant of its delay. Alternatively, if in Experiment 6 the superior recall of the terminal item in the immediate suffix condition was attributable simply to the advanced visual warning of the impending spoken suffix, then, because that same advance warning is now available, a similar pattern of findings should be obtained. That is, increasing suffix delay should result in a larger terminal suffix effect, just as in Experiment 6.

\section{Method}

Participants. The participants were 72 Rice University undergraduates.

Lists. The stimuli were the same as those used in Experiment 6.

Design. The design was the same as that used in Experiment 6. Once again, there was no discernible difference between the data for the two participant groups (i.e., between the effects of 600- and $1,500-\mathrm{msec}$ auditory suffix delays in the delayed suffix conditions), and only the combined data will be reported.

Procedure. The procedure was the same as that in Experiment 6, with the exception of the spatial arrangement of the visual aspects of the last item and the hundred suffix (00). In the immediate suffix condition, the 00 was shown simultaneously with, but $1 \mathrm{~cm}$ below, the last digit. In the delayed suffix condition, the 00 was presented, depending on participant group, either 600 or $1,500 \mathrm{msec}$ after auditory termination of the last digit and in the same place as in the immediate suffix condition (i.e., $1 \mathrm{~cm}$ below the location at which the last digit had been presented).

\section{Results}

Figure 7 shows the serial recall function for each suffix condition. As in Experiment 4, which presented a hundred suffix auditorily, delaying a bimodal hundred suffix had no influence on the suffix effect at the terminal position. The relevant findings are as follows (see also note 6).

1 . With the data averaged across the last four positions, mean probability of recall was higher in the no-suffix condition (.70) than in both the immediate suffix condition (.53) $[t(71)=12.37, p=.000]$ and the delayed suffix condition $(.55)[t(71)=11.32, p=.000]$.

2 . With the data averaged across the last four positions, the delayed suffix effect (.15) was somewhat smaller than the immediate suffix effect (.17), but the difference was unconvincing $[t(71)=1.30, p=.20]$. 


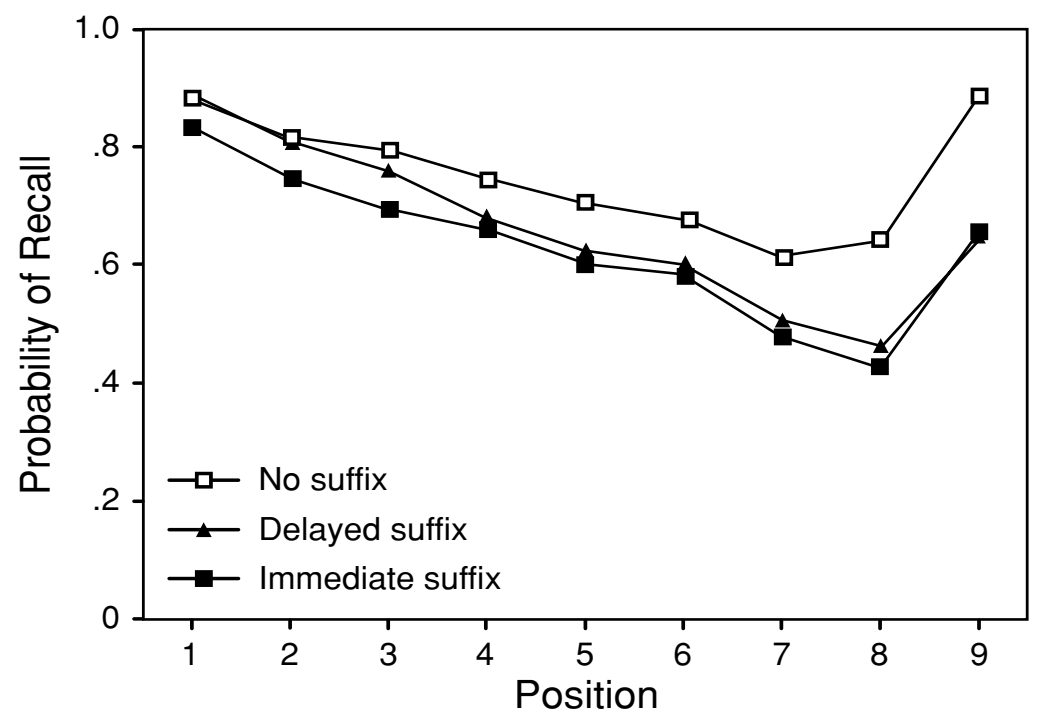

Figure 7. Probability of recall as a function of within-list position and suffix condition (Experiment 7).

3. For the three preterminal positions, although the delayed suffix effect (.12) was somewhat smaller than the immediate suffix effect (.15), the difference was suggestive but not decisive $[t(71)=1.82, p=.07]$.

4. The terminal suffix effect was virtually the same for the delayed suffix condition (.24) and the immediate suffix condition $(.23)[t(71)=0.42, p=.68]$.

5. A 3 (suffix condition) $\times 2$ (position) ANOVA with repeated measures on both variables revealed a convincing interaction between suffix condition and position $\left[F(2,142)=20.72, M S_{\mathrm{e}}=0.006, p=.000\right]$. The difference in the immediate and the delayed suffix effects depended on position, so that the immediate suffix effect was .03 larger than the delayed suffix effect at the preterminal positions but .01 smaller at the terminal position. An ANOVA for just the immediate suffix and delayed suffix data showed that the difference between these suffix effects, as expressed in the delay $\times$ position interaction, was suggestive but less than convincing $[F(1,71)=3.48$, $\left.M S_{\mathrm{e}}=0.007, p=.07\right]$.

The effect of a bimodal hundred suffix on recall of the last list item was essentially invariant of its delay. This finding parallels that of Experiment 4, in which presentation was purely auditory, and it shows that the participants presently did not use the visual information to foster integration of the terminal item and the immediate suffix. Thus, although the terminal suffix effect for spoken digit lists was smaller with an immediate hundred suffix than with a delayed hundred suffix when the concomitant visual-spatial configuration of the terminal item and suffix was meaningful (Experiment 6), this was not the case when the visuospatial configuration was not meaningful (Experiment 7). Moreover, in the immediate suffix condition, recall of the first three items of the list was impaired, relative to the delayed suffix condition, regardless of whether the immediate terminal suffix effect was (Ex- periment 6) or was not (Experiment 7) attenuated relative to the delayed suffix condition.

Across Experiments 6 and 7, then, manipulating the meaningfulness of the visual-spatial configuration of the terminal item and suffix did influence the effect of suffix delay at the terminal position but not the effect at the first few positions. Given that the visual forewarning of the impending spoken suffix in the immediate suffix condition was the same for these two experiments, no support is provided for a forewarning account of the critical findings of Experiment 6-namely, the superior recall of the terminal item in the immediate suffix condition. Furthermore, the observed independence between the effects of suffix delay at the end and at the beginning of the list undermines the possibility that the enhanced recall of the last item in the immediate suffix condition in Experiment 6 was a consequence of additional attention (rehearsal, etc.) being given to the last item at the expense of preceding items (see Salter \& Colley, 1977).

In short, these findings, together with those of Experiments 1-6, advance the case for the terminal suffix effect's being susceptible to the conceptual (semantic) relation between the suffix and the last item of the list, and therefore, they undermine the two-component theory (e.g., Greene, 1992; see also Nairne, 1990; Penney, 1989).

\section{EXPERIMENT 8}

The susceptibility of the terminal suffix effect to concomitant static visual presentation is inconsistent with its interpretation as a wholly bottom-up, structural (precategorical) phenomenon. In Experiment 8, I sought to extend this argument by demonstrating a suffix effect with only static visual presentation.

According to the two-component theory (e.g., Greene, 1992) and other overwriting theories (e.g., Crowder, 1978, 
1983; Crowder \& Morton, 1969; Greene \& Crowder, $1984 b)$, static visual information does not proceed through the same physically sensitive structure or processes as speech-related information and does not survive in iconic (precategorical) form long enough to play a role in most immediate memory procedures. Consistent with this prediction, Greene (1987) failed to obtain a visual suffix effect in any of seven experiments in which supraspan lists were shown both sequentially and simultaneously, with and without the requirement of subvocal articulation, and with a variety of presentation durations. ${ }^{7}$

On the other hand, LeCompte and Watkins (1995, Experiment 5) reported a visual suffix effect, using a procedure highly similar to that used by Greene (1987, Experiment 4), with supraspan lists in which items were shown simultaneously for $4 \mathrm{sec}$. The one departure from Greene's (1987) Experiment 4 was that the participants subvocally mouthed "blah" throughout the study interval. (Although Greene required subvocal articulation during simultaneous visual presentation in his Experiments 6 and 7 , total presentation duration in these experiments was a mere 1.2 sec.) Presumably, the subvocalization increased reliance on visual memory. LeCompte and Watkins (1995) also attenuated the effect of a compound (two-item) suffix by manipulating the font to increase the physical similarity of its constituent elements - thereby, presumably, decreasing the extent to which the compound suffix grouped with the list items. Statistical evaluation of this attenuation was made only for the lists as a whole, although a plot of recall as a function of position (LeCompte \& Watkins, 1995, Figure 5) shows clearly that like the auditory suffix effect, the visual suffix effect was localized toward the end of the list. Overwriting theories in general (e.g., Crowder, 1978, 1983; Greene \& Crowder, 1984b) and the two-component theory in particular either are inconsistent with these findings (e.g., Greene, 1992) or do not address these findings (e.g., Nairne, 1990; Penney, 1985, p. 246).

Experiment 8 was an attempt to replicate and extend LeCompte and Watkins's (1995) findings. If the visual suffix effect they reported really is the same kind of phenomenon as the suffix effect observed with auditory presentation, it should be possible to demonstrate a visual effect analogous to that of the suffix delay obtained with auditory presentation. That is, a suffix that is spatially close to the terminal list item might be expected to impair recall more than does one that is spatially removed from the terminal list item. The specific purpose of Experiment 8 , therefore, was to replicate the finding that recall of the last few items of a statically presented visual list is impaired by a visual suffix and to assess whether this suffix effect would diminish by (spatially) separating the suffix from the list items.

\section{Method}

Participants. The participants were 30 Rice University undergraduates.

Lists. The to-be-remembered items were the digits 0-9, except for 3, which, following LeCompte and Watkins (1995) and Frick and De Rose (1986b), was reserved for use as the suffix. A separate set of 63 digit lists was constructed for each participant. For each list, the digits were chosen randomly, within the constraints that no digit occurred more than once, no digit was one higher or one lower in value than an immediate neighbor, and there were no runs of more than three successive odd digits or three successive even digits. The digits were presented in the center of the monitor in size 18 Courier font.

Design. The experiment conformed to a 3 (suffix condition) $\times 2$ (preterminal and terminal positions) design with repeated measures on both variables. The to-be-remembered digits were always presented in the middle of the monitor, with no spaces between them. To the right of the last (ninth) digit was a white background (control condition), the suffix 3 placed next to the terminal list item (proximal suffix condition), or the suffix 3 separated by two spaces from the terminal list item (distal suffix condition).

Procedure. The participants were given 3 practice trials, 1 in each suffix condition. On each of the 60 trials of the experiment proper, a row of nine digits and, for some trials, a suffix was shown for $4.5 \mathrm{sec}$. The order of the three suffix conditions (control, proximal, and distal) was randomized separately for each participant. The participants were instructed to ignore any concluding 3 and to recall the other nine digits in their presentation order. The participants subvocally mouthed "blah" throughout the study interval at a rate of approximately twice per second. Immediately following list presentation, the nine position (response) markers were shown, and the participants attempted to type the nine digits in their presentation order, beginning with the first digit in the leftmost space and concluding with the ninth digit in the rightmost space. A hyphen was typed for each digit not recalled, and only the most recently typed item could be erased by pressing the Delete key. When satisfied, the participants clicked an "OK" button and were prompted to begin the next trial.

\section{Results}

Figure 8 shows the serial recall function for each suffix condition. In the proximal suffix condition, recall of the last few digits was impaired, relative to the control condition. In contrast, the distal suffix had no clear detrimental effect on recall, relative to the control condition. The relevant findings are as follows. ${ }^{8}$

1. With the data averaged across the last four positions, mean probability of recall in the no-suffix condition (.48) differed from that in the proximal suffix condition (.40) $[t(29)=5.12, p=.000]$, but not from that in the distal suffix condition $(.50)[t(29)=1.50, p=.14]$.

2 . With the data averaged across the last four positions, the proximal suffix effect (.08) was clearly larger than the (nonexistent) distal suffix effect $(-.02)$. The difference was almost certainly not attributable to chance $[t(29)=$ $7.04, p=.000]$.

3. For the three preterminal positions, mean probability of recall was higher in the no-suffix condition (.48) than in the proximal suffix condition (.41) $[t(29)=3.99, p=$ $.000]$, but not higher than in the distal suffix condition (.50) $[t(29)=1.13, p=.27]$. The proximal suffix effect (.07) was clearly larger than the distal suffix effect $(-.02)$ $[t(29)=5.79, p=.000]$.

4. At the terminal position, probability of recall was higher in the no-suffix condition (.50) than in the proximal suffix condition (.39) $[t(29)=4.78, p=.000]$, but not higher than in the distal suffix condition $(.53)[t(29)=$ $1.51, p=.14]$. The proximal suffix effect (.11) was clearly larger than the distal suffix effect $(-.03)$, and the difference was not likely to have arisen by chance $[t(29)=5.08$, $p=.000]$. 


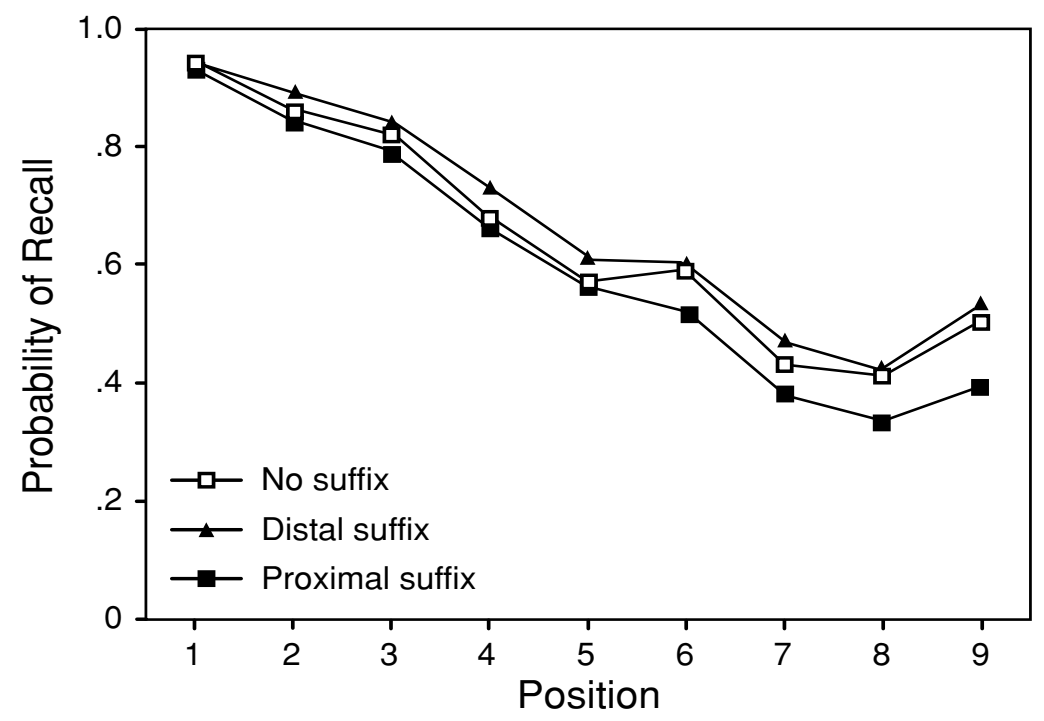

Figure 8. Probability of recall as a function of within-list position and suffix condition (Experiment 8).

5. A 3 (suffix condition) $\times 2$ (position) ANOVA with repeated measures on both variables revealed a marginal interaction between suffix condition and position $\left[F(2,58)=2.94, M S_{\mathrm{e}}=0.005, p=.06\right]$. The proximal suffix effect was larger at the terminal position (.11) than at the preterminal position (.07), although as was shown by the suffix $\times$ position interaction for just the control and proximal suffix data, this difference was less than compelling $\left[F(1,29)=3.76, M S_{\mathrm{e}}=0.005, p=.06\right]$. Finally, there was a tendency for the effect of suffix proximity to be greater at the terminal position (.14) than at the preterminal position (.09), as was shown by the delay $\times$ position interaction for just the proximal and distal suffix data $\left[F(1,29)=4.20, M S_{\mathrm{e}}=0.007, p=.05\right]$.

In short, this experiment demonstrated a suffix effect in the visual modality, using static presentation. Moreover, it did so with a fixed supraspan list length and a lengthy presentation duration, both of these details serving to increase the parallel with the typical auditory suffix effect (see Crowder, 1986; Greene, 1987). In addition, this visual suffix effect was localized toward the end of the list and dissipated when the suffix was separated from the list items, paralleling the effect of temporal separation in the auditory modality. These findings are inconsistent with (e.g., Greene, 1992) or not addressed by (e.g., Nairne, 1990; Penney, 1985, p. 246) the two-component theory.

\section{DISCUSSION}

In this section, I will do four things: (1) summarize the findings of the eight experiments reported here as they pertain to the two-component theory, (2) reconsider the two-component theory, (3) summarize aspects of the present findings that raise problems for other accounts of the suffix effect, and (4) attribute the suffix effect to perceptual grouping.

\section{Summary}

The suffix effect refers to the impairment in recall of the final items of a spoken list produced by appending a nominally irrelevant speech item to the end of the list. According to the two-component theory (e.g., Greene, 1992; see also Nairne, 1990; Penney, 1989), there is a qualitative distinction between the effect at the final position (the terminal suffix effect) and the effect at the immediately preceding positions (the preterminal suffix effect). The terminal suffix effect is posited to be structural, or fixed by the nature of the memory system, whereas the preterminal suffix effect is regarded as mutable and readily susceptible to top-down factors, including conceptual influence and rememberer strategy.

The present investigation provides new evidence demonstrating conceptual influences on the terminal suffix effect, thereby undermining the core assumption of the two-component theory, as well as its proposed qualitative distinction between terminal and preterminal suffix effects. The eight experiments provide three converging lines of evidence.

Experiments 1-3. Experiments 1-3 were performed to investigate the influence of a conceptually based variable - namely, the semantic relationship or conceptual coherence between the suffix and the list items. In Experiments 1 and 3, digits were almost immediately followed by the suffix recall, the suffix hundred, or silence. Contrary to the two-component theory (e.g., Greene, 1992; see also Nairne, 1990; Penney, 1989), but consistent with certain other findings (e.g., Ayres et al., 1979; Salter \& Colley, 1977), increasing the semantic relationship between the suffix and the terminal list item by use of the hundred suffix attenuated the terminal suffix effect.

Experiments 4-7. Experiments 4-7 extended this finding by demonstrating that the semantic relationship or coherence between the suffix and the terminal list 
item modulated the effect of suffix delay. In particular, Experiment 4 showed that relative to a standard suffix (e.g., zero), a hundred suffix attenuated, if not eliminated, the conventional influence of suffix delay at the terminal position. And Experiment 6 demonstrated that a hundred suffix, together with concomitant static visual presentation, reversed the conventional effect of suffix delay, so that the terminal suffix effect increased with suffix delay.

Thus, contrary to the two-component theory (e.g., Greene, 1992; see also Nairne, 1990; Penney, 1989; Penney \& Godsell, 1993), the terminal suffix effect was influenced by two types of top-down, conceptual informationnamely, the semantic relationship between the suffix and the terminal list item and the semantic configuration of concomitant static visual presentation.

Experiment 8. The susceptibility of the terminal suffix effect to concomitant static visual presentation is inconsistent with its interpretation as a wholly bottom-up, structural (precategorical) phenomenon. Experiment 8 extended this argument by demonstrating a suffix effect with only static visual presentation (see also LeCompte \& Watkins, 1995, Experiment 5). Interestingly, the visual suffix effect was localized toward the end of the list, and spatial proximity influenced the visual suffix effect in just the same way that temporal proximity influences the auditory suffix effect (e.g., Bloom \& Watkins, 1999; Crowder, 1971, 1976). These findings are troublesome for speech-related overwriting theories in general (e.g., Crowder, 1978, 1983; Greene \& Crowder, 1984b) and for the two-component theory in particular (e.g., Greene, 1992), because static visual information is assumed neither to be processed through the same physically sensitive structure as that used for speech-related information nor to survive in precategorical form long enough to play a role in most immediate memory procedures (e.g., Crowder, 1978, 1986, 1993; Greene, 1987, 1992). Neither Nairne's (1990) nor Penney's (e.g., 1985, p. 246) two-component model addresses suffix effects obtained solely with static visual presentation.

In short, the eight experiments reported here, together with previous data (e.g., Ayres et al., 1979; Bloom \& Watkins, 1999; Pilotti, Beyer, \& Yasunami, 2002; Salter \& Colley, 1977; Watkins \& Sechler, 1989, Experiment 1), provide converging evidence that is contrary to the core assumption of the two-component theory (e.g., Greene, 1992; see also Nairne, 1990; Penney, 1989) - namely, that the terminal suffix effect is a product of memory structure and beyond top-down, conceptual and strategic influence.

\section{Two-Component Theory Reconsidered}

A proponent of the two-component theory (e.g., Greene, 1992; see also Nairne, 1990; Penney, 1989) or other overwriting theories may maintain that the present findings are beyond the province of the theory, due to some of the presentation modalities employed (e.g., static visual) or because the conceptual nature of some manipulations (e.g., hundred) did not afford a suffix. In response to such a claim, (1) all of the experiments presented distinct list and suffix items, and the manipulations of interest (e.g., hundred) attenuated the suffix effect but did not eliminate it - thus, nominally and functionally, there was a suffixand (2) maintaining that the present findings are beyond the province of the theory carries the cost of failing to provide an account for the findings.

Alternatively, a proponent of the two-component theory may attempt to revise the theory to account for the present findings. ${ }^{9}$ Even if such a revision were successful, each version of the two-component theory (e.g., Greene, 1992; Nairne, 1990; Penney, 1989) is either inconsistent with or does not address certain other findings in the literature (see, e.g., Bloom \& Watkins, 1999; Greene, 1992; LeCompte \& Watkins, 1995).

\section{Alternative Accounts of the Suffix Effect}

Two aspects of the present findings are troublesome for two other accounts of the suffix effect.

Changing-state hypothesis. According to the changingstate hypothesis (Campbell \& Dodd, 1980; see also Campbell, Dodd, \& Brasher, 1983), the suffix effect occurs only with dynamic stimuli-that is, stimuli that change or unfold over time. Campbell and Dodd argued that suffix effects "may reflect a general tendency for changing state information to be processed differently than information (usually visual) which can be resolved simultaneously" (p. 97). Thus, according to the theory, suffix effects arise with gesticulatory (i.e., mouthed, lipread, and handsigned), as well as auditory, presentation, for in each case the stimuli unfold over time. However, the changing-state hypothesis cannot account for the present finding of a suffix effect's being modulated by (Experiment 6), or even the sole consequence of (Experiment 8), static visual stimuli.

Primary linguistic code hypothesis. According to the primary linguistic code hypothesis (Shand \& Klima, 1981), speech (acoustical and gesticulatory) is the primary linguistic code and, hence, the way information is represented in primary memory (Conrad, 1964). In contrast, when information is presented in static visual form, it has to be recoded into the primary linguistic speechbased code. The key assumption is that the suffix effect arises only when stimulus presentation occurs in the primary linguistic code and does not have to be recoded. Although this assumption has received some attention, it has never been fully articulated. This issue aside, the primary linguistic code hypothesis can account for suffix effects obtained with speech-related codes, including speech, mouthed, and lipread stimuli. And if one assumes that for native signers of American Sign Language (ASL), the primary linguistic code is ASL rather than speech, this hypothesis can also account for the demonstration of suffix effects with ASL. However, the primary linguistic code hypothesis cannot account for the present finding of a suffix effect's being modulated by (Experiment 6), or the sole consequence of (Experiment 8), stimuli presented in a secondary code - namely, static visual presentation.

\section{Suffix Effect as Perceptual Grouping}

Rather than modifying any of the aforementioned theories to account for the present findings (see Watkins, 
1990), I conceive of the suffix effect as the product of perceptual grouping (cf. Bloom \& Watkins, 1999; for physically based grouping accounts, see de Gelder \& Vroomen, 1992; Frankish \& Turner, 1984; Kahneman, 1973; Kahneman \& Henik, 1977, 1981; LeCompte \& Watkins, 1995; Nicholls \& Jones, 2002; Rowe \& Rowe, 1976). To the extent that the suffix is perceived as a discrete utterance, as are the list items, it will tend to be grouped with, and impair memory for, those items. The extent of the suffix effect will depend on, among other things, the number of items with which the suffix is perceptually grouped. As with perception in general, the grouping of the suffix and the list items will be influenced by both bottom-up, physically based factors and top-down, conceptually based factors. Thus, on the one hand, to the extent that the suffix is perceived (e.g., Ayres et al., 1979) as physically similar to the list items (e.g., a speech item presented in the same voice, from the same location, and in temporal proximity), it will be more likely to be grouped as another discrete list item, thereby enlarging the suffix effect. And on the other hand, increasing the semantic relatedness between the suffix and the final list item might reasonably be expected to increase the conceptual integration between the suffix and the terminal item, thereby reducing the size of the functional group and attenuating the suffix effect (Experiments 1 and 3), as well as modulating the effect of suffix delay (Experiments 4-7). Moreover, that static visual presentation showed a suffix effect toward the end of the list and that the effect was eliminated through spatial separation (Experiment 8) could reasonably be expected if one assumes that the proximity of the suffix and list items affected their perceptual grouping.

Indeed, bottom-up and top-down instantiations of grouping - particularly, the principles of similarity and proximity - often have been pressed into service to account for a variety of effects that theorists have thought are related to the suffix effect, including standard recency effects (Darwin \& Baddeley, 1974; Frick, 1989a, 1989b; Glenberg, 1990; Nairne, 1990; see also Frankish, 1985, 1989; Greene \& Samuel, 1986), long-term recency effects (Glenberg \& Swanson, 1986; Greene \& Crowder, 1984a; Neath, 1993; Neath \& Crowder, 1990; Thapar \& Greene, 1993; Watkins \& Peynircioğlu, 1983), standard modality effects (e.g., Darwin \& Baddeley, 1974; Frankish, 1985; Frick, 1989a; Glenberg, Mann, Altman, Forman, $\&$ Procise, 1989; Murray et al., 1999; Nairne, 1990), and long-term modality effects (Glenberg, 1984; Glenberg \& Swanson, 1986; Greene, 1985; Marks \& Crowder, 1997; Neath \& Crowder, 1990). Certainly, then, a grouping account will foster the integration of the suffix effect with other memory phenomena.

\section{REFERENCES}

Ayres, T. J., Jonides, J., Reitman, J. S., Egan, J. C., \& Howard, D. A. (1979). Differing suffix effects for the same physical suffix. Journal of Experimental Psychology: Human Learning \& Memory, 5, 315321.

Ayres, T. J., Naveh-Benjamin, M., \& Jonides, J. (1986). Recognition of the stimulus suffix. Journal of Memory \& Language, 25, 619-626.
Baddeley, A., \& Hull, A. (1979). Prefix and suffix effects: Do they have a common basis? Journal of Verbal Learning \& Verbal Behavior, 18, 129-140.

Balota, D. A., \& DucheK, J. M. (1986). Voice-specific information and the 20-second delayed-suffix effect. Journal of Experimental Psychology: Learning, Memory, \& Cognition, 12, 509-516.

Balota, D. A., \& Engle, R. W. (1981). Structural and strategic factors in the stimulus suffix effect. Journal of Verbal Learning \& Verbal Behavior, 20, 346-357.

BLoom, L. C., \& WATKINS, M. J. (1999). Two-component theory of the suffix effect: Contrary findings. Journal of Experimental Psychology: Learning, Memory, \& Cognition, 25, 1452-1474.

CAMPBEll, R., \& DodD, B. (1980). Hearing by eye. Quarterly Journal of Experimental Psychology, 32, 85-99.

CAmpbell, R., Dodd, B., \& Brasher, J. (1983). The sources of visual recency: Movement and language in serial recall. Quarterly Journal of Experimental Psychology, 35A, 571-587.

Campbell, R., Garwood, J., \& Rosen, S. (1988). Adding sound to lipread lists: The effects on serial recall of adding an auditory pulse train and a pure tone to silently lipread lists. Memory \& Cognition, 16, 210-219.

Conrad, R. (1964). Acoustic confusions in immediate memory. British Journal of Psychology, 55, 75-84.

Cowan, N. (1984). On short and long auditory stores. Psychological Bulletin, 96, 341-370.

Cowan, N., \& Kielbasa, L. (1986). Temporal properties of memory for speech in preschool children. Memory \& Cognition, 14, 382-390.

Craik, F. I. M., \& Lockhart, R. S. (1972). Levels of processing: A framework for memory research. Journal of Verbal Learning \& Verbal Behavior, 11, 671-684.

Crowder, R. G. (1967). Prefix effects in immediate memory. Canadian Journal of Psychology, 21, 450-461.

Crowder, R. G. (1969). Improved recall for digits with delayed recall cues. Journal of Experimental Psychology, 82, 258-262.

Crowder, R. G. (1970). The role of one's own voice in immediate memory. Cognitive Psychology, 1, 157-178.

Crowder, R. G. (1971). Waiting for the stimulus suffix: Decay, delay, rhythm, and readout in immediate memory. Quarterly Journal of Experimental Psychology, 23, 324-340.

Crowder, R. G. (1972). Visual and auditory memory. In J. F. Kavanagh \& I. G. Mattingly (Eds.), Language by ear and by eye: The relationships between speech and reading (pp. 251-275). Cambridge, MA: MIT Press.

Crowder, R. G. (1976). Principles of learning and memory. Hillsdale, NJ: Erlbaum.

Crowder, R. G. (1978). Mechanisms of auditory backward masking in the stimulus suffix effect. Psychological Review, 85, 502-524.

Crowder, R. G. (1982). Disinhibition of masking in auditory sensory memory. Memory \& Cognition, 10, 424-433.

Crowder, R. G. (1983). The purity of auditory memory. Philosophical Transactions of the Royal Society of London: Series B, 302, 251-265.

Crowder, R. G. (1986). Auditory and temporal factors in the modality effect. Journal of Experimental Psychology: Learning, Memory, \& Cognition, 12, 268-275.

Crowder, R. G. (1993). Auditory memory. In S. McAdams \& E. Bigand (Eds.), Thinking in sound: The cognitive psychology of human audition (pp. 113-145). Oxford: Oxford University Press.

Crowder, R. G., \& Morton, J. (1969). Precategorical acoustic storage (PAS). Perception \& Psychophysics, 5, 365-373.

Crowder, R. G., \& RaEburn, V. P. (1970). The stimulus suffix with reversed speech. Journal of Verbal Learning \& Verbal Behavior, $\mathbf{9}$, 342-345.

Dallett, K. M. (1965). "Primary memory": The effects of redundancy upon digit repetition. Psychonomic Science, 3, 237-238.

Darwin, C. J., \& BadDeley, A. D. (1974). Acoustic memory and the perception of speech. Cognitive Psychology, 6, 41-60.

de Gelder, B., \& Vroomen, J. (1992). Abstract versus modalityspecific memory representations in processing auditory and visual speech. Memory \& Cognition, 20, 533-538.

ENGLE, R. W. (1974). The modality effect: Is precategorical acoustic storage responsible? Journal of Experimental Psychology, 102, 824-829. 
ENGLE, R. W. (1980). The suffix effect: How many positions are involved? Memory \& Cognition, 8, 247-252.

Fabiani, M., \& Donchin, E. (1995). Encoding processes and memory organization: A model of the von Restorff effect. Journal of Experimental Psychology: Learning, Memory, \& Cognition, 21, 224-240.

FranKISH, C. (1985). Modality-specific grouping effects in short-term memory. Journal of Memory \& Language, 24, 200-209.

Frankish, C. (1989). Perceptual organization and precategorical acoustic storage. Journal of Experimental Psychology: Learning, Memory, \& Cognition, 15, 469-479.

Frankish, C., \& TURner, J. (1984). Delayed suffix effect at very short delays. Journal of Experimental Psychology: Learning, Memory, \& Cognition, 10, 767-777.

FrICK, R. W. (1988). The role of memory in attenuations of the suffix effect. Memory \& Cognition, 16, 15-22.

FrICK, R. W. (1989a). Explanations of grouping in immediate ordered recall. Memory \& Cognition, 17, 551-562.

FrICK, R. W. (1989b). Recency and the modality effect in immediate ordered recall. Canadian Journal of Psychology, 43, 494-511.

Frick, R. W., \& De Rose, A. (1986a). Attenuating the visual suffix effect with color. Memory \& Cognition, 14, 391-397.

FrICK, R. W., \& De Rose, A. (1986b). The suffix effect and preattentive unit-formation in visual short-term memory. Canadian Journal of Psychology, 40, 97-108.

Glenberg, A. M. (1984). A retrieval account of the long-term modality effect. Journal of Experimental Psychology: Learning, Memory, \& Cognition, 10, 16-31.

GlenberG, A. M. (1990). Common processes underlie enhanced recency effects for auditory and changing-state stimuli. Memory \& Cognition, 18, 638-650.

Glenberg, A. M., Mann, S., Altman, L., Forman, T., \& Procise, S. (1989). Modality effects in the coding and reproduction of rhythms. Memory \& Cognition, 17, 373-383.

Glenberg, A. M., \& Swanson, N. G. (1986). A temporal distinctiveness theory of recency and modality effects. Journal of Experimental Psychology: Learning, Memory, \& Cognition, 12, 3-15.

GreEnberG, S. N., \& ENGLE, R. W. (1983). Voice change in the stimulus suffix effect: Are the effects structural or strategic? Memory \& Cognition, 11, 551-556.

Greene, R. L. (1985). Constraints on the long-term modality effect. Journal of Memory \& Language, 24, 526-541.

Greene, R. L. (1987). Stimulus suffixes and visual presentation. Memory \& Cognition, 15, 497-503.

GreENe, R. L. (1988). Stimulus suffix effects in recognition memory. Memory \& Cognition, 16, 206-209.

GreEne, R. L. (1991). Serial recall of two-voice lists: Implications for theories of auditory recency and suffix effects. Memory \& Cognition, 19, 72-78.

GreEne, R. L. (1992). Human memory: Paradigms and paradoxes. Hillsdale, NJ: Erlbaum.

Greene, R. L., \& Crowder, R. G. (1984a). Effects of semantic similarity on long-term recency. American Journal of Psychology, 97, 441-449.

Greene, R. L., \& Crowder, R. G. (1984b). Modality and suffix effects in the absence of auditory stimulation. Journal of Verbal Learning \& Verbal Behavior, 23, 371-382.

Greene, R. L., \& Crowder, R. G. (1988). Memory for serial position: Effects of spacing, vocalization, and stimulus suffixes. Journal of Experimental Psychology: Learning, Memory, \& Cognition, 14, 740-748.

Greene, R. L., Elliott, C. L., \& Smith, M. D. (1988). When do interleaved suffixes improve recall? Journal of Memory \& Language, 27, 560-571.

Greene, R. L., \& SAmuel, A. G. (1986). Recency and suffix effects in serial recall of musical stimuli. Journal of Experimental Psychology: Learning, Memory, \& Cognition, 12, 517-524.

HARRIS, R. W. (1989). The stimulus suffix effect and positional uncertainty. Canadian Journal of Psychology, 43, 74-87.

HiтcH, G. J. (1975). The role of attention in visual and auditory suffix effects. Memory \& Cognition, 3, 501-505.

HunT, R. R. (1995). The subtlety of distinctiveness: What von Restorff really did. Psychonomic Bulletin \& Review, 2, 105-112.
Kahneman, D. (1973). Attention and effort. Englewood Cliffs, NJ: Prentice Hall.

Kahneman, D., \& HenIK, A. (1977). Effects of visual grouping on immediate recall and selective attention. In S. Dornic (Ed.), Attention and performance VI (pp. 307-332). Hillsdale, NJ: Erlbaum.

Kahneman, D., \& Henik, A. (1981). Perceptual organization and attention. In M. Kubovy \& J. Pomerantz (Eds.), Perceptual organization (pp. 181-213). Hillsdale, NJ: Erlbaum.

LeCompte, D. C., \& WatKIns, M. J. (1993). Similarity as an organising principle in short-term memory. Memory, 1, 3-22.

LeCompte, D. C., \& Watkins, M. J. (1995). Grouping in primary memory: The case of the compound suffix. Journal of Experimental Psychology: Learning, Memory, \& Cognition, 21, 96-102.

MARKs, A. R., \& Crowder, R. G. (1997). Temporal distinctiveness and modality. Journal of Experimental Psychology: Learning, Memory, \& Cognition, 4, 164-180.

Miles, C., Westley, D. P., \& Buller, M. J. (1995). Postcategorical processing and attenuation of the auditory suffix: Evidence from both immediate and delayed suffixes. Acta Psychologica, 89, 261-282.

Morton, J. (1976). Two mechanisms in the stimulus suffix effect. Memory \& Cognition, 4, 144-149.

Morton, J., Crowder, R. G., \& Prussin, H. A. (1971). Experiments with the stimulus suffix effect. Journal of Experimental Psychology Monograph, 91, 169-190.

Morton, J., \& Holloway, C. M. (1970). Absence of a cross-modal "suffix effect" in short-term memory. Quarterly Journal of Experimental Psychology, 22, 167-176.

Morton, J., Marcus, S. M., \& Ottley, P. (1981). The acoustic correlates of "speechlike": A use of the suffix effect. Journal of Experimental Psychology: General, 110, 568-593.

Murray, D. J., Boudreau, N., Burggraf, K. K., Dobell, L., Guger, S. L., LEASK, A., ET AL. (1999). A grouping interpretation of the modality effect in immediate probed recognition. Memory \& Cognition, 27, 234-245.

NAIRne, J. S. (1990). A feature model of immediate memory. Memory \& Cognition, 18, 251-269.

Nairne, J. S., \& Crowder, R. G. (1982). On the locus of the stimulus suffix effect. Memory \& Cognition, 10, 350-357.

Nairne, J. S., \& Walters, V. L. (1983). Silent mouthing produces modality- and suffix-like effects. Journal of Verbal Learning \& Verbal Behavior, 22, 475-483.

NeAth, I. (1993). Contextual and distinctive processes and the serial position function. Journal of Memory \& Language, 32, 820-840.

Neath, I., \& Crowder, R. G. (1990). Schedules of presentation and temporal distinctiveness in human memory. Journal of Experimental Psychology: Learning, Memory, \& Cognition, 16, 316-327.

Neath, I., \& Surprenant, A. M. (2003). Human memory: An introduction to research, data, and theory (2nd ed.). Belmont, CA: Wadsworth.

Neath, I., Surprenant, A. M., \& Crowder, R. G. (1993). The contextdependent stimulus suffix effect. Journal of Experimental Psychology: Learning, Memory, \& Cognition, 19, 698-703.

Nicholls, A. P., \& Jones, D. M. (2002). Capturing the suffix: Cognitive streaming in immediate serial recall. Journal of Experimental Psychology: Learning, Memory, \& Cognition, 28, 12-28.

Ottley, P., Marcus, S., \& Morton, J. (1982). Contextual effects in the stimulus suffix paradigm. British Journal of Psychology, 73, 383-387.

PenNey, C. G. (1979). Interactions of suffix effects with suffix delay and recall modality in serial recall. Journal of Experimental Psychology: Human Learning \& Memory, 5, 507-521.

PENNEY, C. G. (1985). Elimination of the suffix effect on preterminal list items with unpredictable list length: Evidence for a dual model of suffix effects. Journal of Experimental Psychology: Learning, Memory, \& Cognition, 11, 229-247.

Penney, C. G. (1989). Modality effects and the structure of short-term verbal memory. Memory \& Cognition, 17, 398-422.

Penney, C. G., \& Godsell, A. (1993). Suffix delay and the terminal and preterminal suffix effects. Canadian Journal of Experimental Psychology, 47, 467-476.

Pilotti, M., Beyer, T., \& Yasunami, M. (2002). Top-down processing and the suffix effect in young and older adults. Memory \& Cognition, 30, 89-96. 
Rowe, E. J., \& Rowe, W. G. (1976). Stimulus suffix effects with speech and nonspeech sounds. Memory \& Cognition, 4, 128-131.

Salter, D., \& Colley, J. G. (1977). The stimulus suffix: A paradoxical effect. Memory \& Cognition, 5, 257-262.

Shand, M. A., \& Klima, E. S. (1981). Nonauditory suffix effects in congenitally deaf signers of American Sign Language. Journal of Experimental Psychology: Human Learning \& Memory, 7, 464-474.

Spoenr, K. T., \& Corin, W. J. (1978). The stimulus suffix effect as a memory coding phenomenon. Memory \& Cognition, 6, 583-589.

Thapar, A., \& GReEnE, R. L. (1993). Evidence against a short-termstore account of long-term recency effects. Memory \& Cognition, 21, 329-337.

vON Restorff, H. (1933). Über die Wirkung von Bereichsbildungen im Spurenfeld. Psychologische Forschung, 18, 299-342.

WALLACE, W. P. (1965). Review of the historical, empirical, and theoretical status of the von Restorff phenomenon. Psychological Bulletin, 63, 410-424.

WatKIns, M. J. (1990). Mediationism and the obfuscation of memory. American Psychologist, 45, 328-335.

WATKIns, M. J., \& PeYNiRCioĞLu, Z. F. (1983). Three recency effects at the same time. Journal of Verbal Learning \& Verbal Behavior, 22, 375-384.

WATKINS, M. J., \& SechleR, E. S. (1989). Adapting to an irrelevant item in an immediate recall task. Memory \& Cognition, 17, 682-692.

\section{NOTES}

1. See Ayres, Naveh-Benjamin, and Jonides, 1986; Baddeley and Hull, 1979; Balota and Duchek, 1986; Balota and Engle, 1981; Bloom and Watkins, 1999; Campbell, Garwood, and Rosen, 1988; Cowan, 1984; Cowan and Kielbasa, 1986; Engle, 1980; Greene, 1988, 1991, 1992; Greene and Crowder, 1988; Greene et al., 1988; Greene and Samuel, 1986; Harris, 1989; LeCompte and Watkins, 1993; Miles, Westley, and Buller, 1995; Nairne, 1990; Nairne and Crowder, 1982; Neath, Surprenant, and Crowder, 1993; Nicholls and Jones, 2002; Penney, 1985, 1989; Penney and Godsell, 1993; Pilotti, Beyer, and Yasunami, 2002; Watkins and Sechler, 1989; see also Crowder, 1982, 1986; Frick, 1988; Greenberg and Engle, 1983; Morton, 1976; Morton and Holloway, 1970; Morton et al., 1981.

2. Point 5 is based on two ANOVAs: a suffix condition $\times$ position analysis, in which the preterminal and the terminal positions were given equal weight, and a suffix condition $\times$ position analysis for just the $r e$ call and hundred suffix conditions, in which the preterminal and the terminal positions were given equal weight. Both ANOVAs took account of the repetition of measures on the suffix and position variables. Other findings from these analyses are included in the Appendix.

3. Throughout the article, $M S_{\mathrm{e}}$ values will be rounded to three decimal places, and $p$ values will be rounded to the number of decimal places shown.

4. Point 5 is based on two ANOVAs: a suffix condition $\times$ position analysis, in which the preterminal and the terminal positions were given equal weight, and a suffix condition $\times$ position analysis for just the callre and dredhun suffix conditions, in which the preterminal and the terminal positions were given equal weight. Both ANOVAs took account of the repetition of measures on the suffix and position variables. Other findings from these analyses are included in the Appendix.

5. Point 5 is based on four ANOVAs: a suffix condition $\times$ position analysis, in which the preterminal and the terminal positions were given equal weight; a suffix condition $\times$ position analysis for just the recall and hundred suffix conditions, in which the preterminal and the terminal positions were given equal weight; a suffix condition $\times$ position analysis for just the recall and through-list hundred suffix conditions, in which the preterminal and the terminal positions were given equal weight; and a suffix condition $\times$ position analysis for just the through-list hundred and hundred suffix conditions, in which the preterminal and the terminal positions were given equal weight. All the ANOVAs took account of the repetition of measures on the suffix and position variables. Other findings from these analyses are included in the Appendix.

6. For Experiments 4-7, Point 5 in the Results section is based on two ANOVAs: a suffix condition $\times$ position analysis, in which the preterminal and the terminal positions were given equal weight, and a suffix condition $\times$ position analysis for just the immediate and delayed suffix conditions, in which the preterminal and the terminal positions were given equal weight. Both ANOVAs took account of the repetition of measures on the suffix and position variables. Other findings from these analyses are included in the Appendix.

7. Specifically, Greene (1987) failed to replicate the visual suffix effects documented in each of three previous reports (Frick \& De Rose, 1986b; Hitch, 1975; Kahneman, 1973). Even had the effects been replicated, it can be argued that the findings documented in the three reports do not seriously challenge bottom-up, overwriting accounts of the suffix effect (see Crowder, 1986; Greene, 1987). First, Kahneman used such a brief presentation duration that, as some have argued, his findings may be better cast in perceptual, rather than mnemonic, terms. Second, as has been noted by some, although Frick and De Rose (1986b) used a presentation duration more characteristic of auditory suffix experiments, their lists, unlike typical auditory lists, were not of predictable supraspan length. Third, Hitch presented the suffix and no-suffix lists in separate blocks, thereby making the suffix predictable.

8. Point 5 is based on three ANOVAs: a suffix condition $\times$ position analysis, in which the preterminal and the terminal positions were given equal weight; a suffix condition $\times$ position analysis for just the control and proximal suffix conditions, in which the preterminal and the terminal positions were given equal weight; and a suffix condition $\times$ position analysis for just the proximal and distal suffix conditions, in which the preterminal and the terminal positions were given equal weight. All the ANOVAs took account of the repetition of measures on the suffix and position variables. Other findings from these analyses are included in the Appendix.

9. Neath et al. (1993) demonstrated a top-down, context-sensitive suffix effect at the terminal position and offered an explanation that was based on a post hoc interpretation of Nairne's (1990) feature model account of the suffix effect. Whereas Nairne attributed the terminal suffix effect to the overwriting of physical, modality-dependent features, Neath et al. attributed the context-sensitive terminal suffix effect to interference between modality-independent features. Neath et al. assumed that the context-sensitive sheep suffix differed in its modality-independent features - and therefore, in its feature similarity to the final list itemdepending on whether it was categorized as a bleating sheep (animal) or a verbal utterance (human). No explicit account was offered for the specific, asymmetric patterns of suffix effects at both the terminal and the preterminal positions in Experiment 2 (see their Figures $2 b$ and $2 c$ ). Specifically, when recall of the critical verbal lists that were followed by an animal sheep sound (control lists) was compared with that for lists followed by a human sheep utterance (suffix lists), it appears that, for the human-animal group (Figure 2b), a suffix effect was obtained at both the terminal and the preterminal list positions, but for the animal-human group (Figure 2c), no suffix effect was obtained at the terminal position, and a reverse suffix effect was obtained at the preterminal positions. 


\section{APPENDIX}

Reported here are additional findings from the ANOVAs. In all cases, the dependent variable is the mean probability of recall for the serial positions or position specified. Thus, for effects involving position, the preterminal position was weighted the same as the terminal position, despite being based on more data.

\section{Experiment 1}

Here, preterminal refers to Positions 6-8. Measures were repeated on both the suffix condition and the position variables.

The 3 (suffix condition) $\times 2$ (position) analysis revealed the following: For the main effect of suffix condition, $F(2,46)=49.98, M S_{\mathrm{e}}=0.021, p=.000$, and for the main effect of position, $F(1,23)=14.33, M S_{\mathrm{e}}=$ $0.043, p=.001$.

The 2 (suffix) $\times 2$ (position) analysis of the data for just the hundred and recall suffix data revealed the following: For the main effect of suffix condition, $F(1,23)=7.78, M S_{\mathrm{e}}=0.026, p=.01$, and for the main effect of position, $F(1,23)=4.86, M S_{\mathrm{e}}=0.033, p=.038$.

\section{Experiment 2}

Here, preterminal refers to Positions 6-8. Measures were repeated on both the suffix condition and the position variables.

The 3 (suffix condition) $\times 2$ (position) analysis revealed the following: For the main effect of suffix condition, $F(2,46)=70.49, M S_{\mathrm{e}}=0.015, p=.000$, and for the main effect of position, $F(1,23)=16.45, M S_{\mathrm{e}}=$ $0.048, p=.000$.

The 2 (suffix) $\times 2$ (position) analysis of the data for just the dredhun and callre suffix data revealed the following: For the main effect of suffix condition, $F(1,23)=1.53, M S_{\mathrm{e}}=0.011, p=.23$, and for the main effect of position, $F(1,23)=2.16, M S_{\mathrm{e}}=0.040, p=.16$.

\section{Experiment 3}

Here, preterminal refers to Positions 6-8. Measures were repeated on both the suffix condition and the position variables.

The 4 (suffix condition) $\times 2$ (position) analysis revealed the following: For the main effect of suffix condition, $F(3,69)=38.92, M S_{\mathrm{e}}=0.012, p=.000$, and for the main effect of position, $F(1,23)=22.70, M S_{\mathrm{e}}=$ $0.047, p=.000$.

The 2 (suffix) $\times 2$ (position) analysis of the data for just the hundred and recall suffix data revealed the following: For the main effect of suffix condition, $F(1,23)=10.51, M S_{\mathrm{e}}=0.008, p=.004$, and for the main effect of position, $F(1,23)=8.61, M S_{\mathrm{e}}=0.022, p=.007$.

The 2 (suffix) $\times 2$ (position) analysis of the data for just the through-list hundred and recall suffix data revealed the following: For the main effect of suffix condition, $F(1,23)=1.95, M S_{\mathrm{e}}=0.012, p=.18$, and for the main effect of position, $F(1,23)=13.19, M S_{\mathrm{e}}=0.018, p=.001$.

The 2 (suffix) $\times 2$ (position) analysis of the data for just the hundred and through-list hundred suffix data revealed the following: For the main effect of suffix condition, $F(1,23)=3.14, M S_{\mathrm{e}}=0.006, p=.09$, and for the main effect of position, $F(1,23)=21.44, M S_{\mathrm{e}}=0.03, p=.000$.

\section{Experiment 4}

Here, preterminal refers to Positions 6-8. Measures were repeated on both the suffix condition and the position variables.

The 3 (suffix condition) $\times 2$ (position) analysis revealed the following: For the main effect of suffix condition, $F(2,142)=102.00, M S_{\mathrm{e}}=0.016, p=.000$, and for the main effect of position, $F(1,71)=148.00, M S_{\mathrm{e}}=$ $0.032, p=.000$.

The 2 (suffix) $\times 2$ (position) analysis of the data for just the immediate and delayed suffix data revealed the following: For the main effect of suffix condition, $F(1,71)=0.97, M S_{\mathrm{e}}=0.017, p=.33$, and for the main effect of position, $F(1,71)=88.53, M S_{\mathrm{e}}=0.025, p=.000$.

\section{Experiment 5}

Here, preterminal refers to Positions 6-8. Measures were repeated on both the suffix condition and the position variables.

The 3 (suffix condition) $\times 2$ (position) analysis revealed the following: For the main effect of suffix condition, $F(2,64)=72.63, M S_{\mathrm{e}}=0.012, p=.000$, and for the main effect of position, $F(1,32)=35.60, M S_{\mathrm{e}}=$ $0.026, p=.000$.

The 2 (suffix) $\times 2$ (position) analysis of the data for just the immediate and delayed suffix data revealed the following: For the main effect of suffix condition, $F(1,32)=7.47, M S_{\mathrm{e}}=0.011, p=.01$, and for the main effect of position, $F(1,32)=7.76, M S_{\mathrm{e}}=0.028, p=.009$. 


\section{APPENDIX (Continued)}

\section{Experiment 6}

Here, preterminal refers to Positions 6-8. Measures were repeated on both the suffix condition and the position variables.

The 3 (suffix condition) $\times 2$ (position) analysis revealed the following: For the main effect of suffix condition, $F(2,142)=118.00, M S_{\mathrm{e}}=0.013, p=.000$, and for the main effect of position, $F(1,71)=173.00, M S_{\mathrm{e}}=$ $0.047, p=.000$.

The 2 (suffix) $\times 2$ (position) analysis of the data for just the immediate and delayed suffix data revealed the following: For the main effect of suffix condition, $F(1,71)=14.12, M S_{\mathrm{e}}=0.016, p=.000$, and for the main effect of position, $F(1,71)=128.00, M S_{\mathrm{e}}=0.035, p=.000$.

\section{Experiment 7}

Here, preterminal refers to Positions 6-8. Measures were repeated on both the suffix condition and the position variables.

The 3 (suffix condition) $\times 2$ (position) analysis revealed the following: For the main effect of suffix condition, $F(2,142)=113.00, M S_{\mathrm{e}}=0.015, p=.000$, and for the main effect of position, $F(1,71)=85.30, M S_{\mathrm{e}}=$ $0.039, p=.000$.

The 2 (suffix) $\times 2$ (position) analysis of the data for just the immediate and delayed suffix data revealed the following: For the main effect of suffix condition, $F(1,71)=0.41, M S_{\mathrm{e}}=0.016, p=.52$, and for the main effect of position, $F(1,71)=51.25, M S_{\mathrm{e}}=0.029, p=.000$.

\section{Experiment 8}

Here, preterminal refers to Positions 6-8. Measures were repeated on both the suffix condition and the position variables.

The 3 (suffix condition) $\times 2$ (position) analysis revealed the following: For the main effect of suffix condition, $F(2,58)=27.26, M S_{\mathrm{e}}=0.008, p=.000$, and for the main effect of position, $F(1,29)=0.35, M S_{\mathrm{e}}=$ $0.024, p=.562$.

The 2 (suffix) $\times 2$ (position) analysis of the data for just the control and proximal suffix data revealed the following: For the main effect of suffix condition, $F(1,29)=30.24, M S_{\mathrm{e}}=0.008, p=.000$, and for the main effect of position, $F(1,29)=0.002, M S_{\mathrm{e}}=0.018, p=.964$.

The 2 (suffix) $\times 2$ (position) analysis of the data for just the proximal and distal suffix data revealed the following: For the main effect of suffix condition, $F(1,29)=44.47, M S_{\mathrm{e}}=0.009, p=.000$, and for the main effect of position, $F(1,29)=0.11, M S_{\mathrm{e}}=0.017, p=.746$. 